Article

\title{
Effects of UV-A Light Treatment on Ammonia, Hydrogen Sulfide, Greenhouse Gases, and Ozone in Simulated Poultry Barn Conditions
}

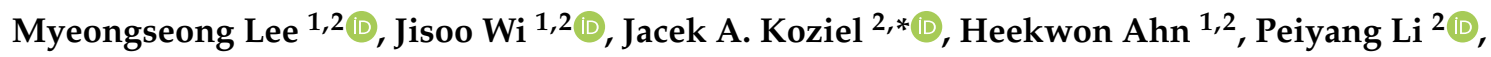 \\ Baitong Chen ${ }^{2}\left(\mathbb{D}\right.$, Zhanibek Meiirkhanuly ${ }^{2}$, Chumki Banik ${ }^{2} \mathbb{D}$ and William Jenks ${ }^{3}$ \\ 1 Department of Animal Biosystems Sciences, Chungnam National University, Daejeon 34134, Korea; \\ leefame@iastate.edu (M.L.); jswi@cnu.ac.kr (J.W.); hkahn@cnu.ac.kr (H.A.) \\ 2 Department of Agricultural and Biosystems Engineering, Iowa State University, Ames, IA 50011, USA; \\ peiyangl@iastate.edu (P.L.); baitongc@iastate.edu (B.C.); zhanibek@iastate.edu (Z.M.); \\ cbanik@iastate.edu (C.B.) \\ 3 Department of Chemistry, Iowa State University, Ames, IA 50011, USA; wsjenks@iastate.edu \\ * Correspondence: koziel@iastate.edu; Tel.: +1-515-294-4206
}

Received: 14 February 2020; Accepted: 9 March 2020; Published: 14 March 2020

check for updates

\begin{abstract}
Gaseous emissions, a side effect of livestock and poultry production, need to be mitigated to improve sustainability. Emissions of ammonia $\left(\mathrm{NH}_{3}\right)$, hydrogen sulfide $\left(\mathrm{H}_{2} \mathrm{~S}\right)$, greenhouse gases (GHGs), and odorous volatile organic compounds (VOCs) have a detrimental effect on the environment, climate, and quality of life in rural communities. We are building on previous research to bring advanced oxidation technologies from the lab to the farm. To date, we have shown that ultraviolet A (UV-A) has the potential to mitigate selected odorous gases and GHGs in the context of swine production. Much less research on emissions mitigation has been conducted in the context of poultry production. Thus, the study objective was to investigate whether the UV-A can mitigate $\mathrm{NH}_{3}$, $\mathrm{H}_{2} \mathrm{~S}$, GHGs, and $\mathrm{O}_{3}$ in the simulated poultry barn environment. The effects of several variables were tested: the presence of photocatalyst, relative humidity, treatment time, and dust accumulation under two different light intensities (facilitated with fluorescent and light-emitting diode, LED, lamps). The results provide evidence that photocatalysis with $\mathrm{TiO}_{2}$ coating and UV-A light can reduce gas concentrations of $\mathrm{NH}_{3}, \mathrm{CO}_{2}, \mathrm{~N}_{2} \mathrm{O}$, and $\mathrm{O}_{3}$, without a significant effect on $\mathrm{H}_{2} \mathrm{~S}$ and $\mathrm{CH}_{4}$. The particular $\%$ reduction depends on the presence of photocatalysts, relative humidity $(\mathrm{RH})$, light type (intensity), treatment time, and dust accumulation on the photocatalyst surface. In the case of $\mathrm{NH}_{3}$, the reduction varied from $2.6-18.7 \%$ and was affected by $\mathrm{RH}$ and light intensity. The \% reduction of $\mathrm{NH}_{3}$ was the highest at $12 \% \mathrm{RH}$ and increased with treatment time and light intensity. The \% reduction of $\mathrm{NH}_{3}$ decreased with the accumulation of poultry dust. The \% reduction for $\mathrm{H}_{2} \mathrm{~S}$ had no statistical difference under any experimental conditions. The proposed treatment of $\mathrm{NH}_{3}$ and $\mathrm{H}_{2} \mathrm{~S}$ was evaluated for a potential impact on important ambient air quality parameters, the possibility of simultaneously mitigating or generating GHGs. There was no statistically significant change in $\mathrm{CH}_{4}$ concentrations under any experimental conditions. $\mathrm{CO}_{2}$ was reduced at $3.8 \%-4.4 \% . \mathrm{N}_{2} \mathrm{O}$ and $\mathrm{O}_{3}$ concentrations were reduced by both direct photolysis and photocatalysis, with the latter having greater $\%$ reductions. As much as $6.9-12.2 \%$ of the statistically-significant mitigation of $\mathrm{N}_{2} \mathrm{O}$ was observed. The \% reduction for $\mathrm{O}_{3}$ ranged from $12.4-48.4 \%$. The results warrant scaling up to a pilot-scale where the technology could be evaluated with economic analyses.
\end{abstract}

Keywords: air pollution, air quality; poultry; livestock; photocatalysis; photolysis; LED UV; odor; titanium dioxide; emissions 


\section{Introduction}

Gaseous emissions, an unwanted side effect of livestock and poultry production, must be mitigated to improve the sustainability of the industry [1]. This is because the gaseous emissions include various components such as ammonia $\left(\mathrm{NH}_{3}\right)$, hydrogen sulfide $\left(\mathrm{H}_{2} \mathrm{~S}\right)$, greenhouse gases (GHGs), and odorous volatile organic compounds (VOCs) that have a detrimental effect on the environment, climate, and quality of life in rural communities [2,3]. Maurer et al. [4] reported on the effectiveness of technologies to reduce gas emissions from livestock and poultry housing, manure storage and treatment, and land application. The maturity and the number of technologies for poultry housing are far below those available for the swine industry [4].

Mitigation technologies can be divided into 'end-of-pipe' and 'source-based' types [5]. The sourcebased solution is a method of treating the manure as a source of emissions, such as surficial application of biochar [6], soybean peroxidase [7-9], zeolites and bentonites [10,11], urease inhibitors [12,13], feed additives [14], and manure aeration [15]. The end-of-pipe approach is the physicochemical and biological treatment for mitigating emissions from, for example, barns. Typical examples of the end-of-pipe solution are the use of biofilters [16,17] and scrubbers. Ultraviolet light (UV) can be considered as both end-of-pipe (treating exhaust air from barns) and a source-based (e.g., for improvement of indoor air quality; inside the barn) [1,18-21].

Near-UV (UV-A) irradiative treatment has been evaluated to reduce gas and fine particulate concentrations inside a swine barn as well as for increased feed conversion rates that lower the carbon footprint and improves the sustainability [18]. The ultraviolet range is traditionally broken up into wavelength ranges, labeled $\mathrm{A}, \mathrm{B}$, and $\mathrm{C}$, corresponding to progressively shorter and more destructive wavelengths. UV-A (roughly $320-400 \mathrm{~nm}$ ) is the least toxic of the UV range and is commonly used in commercial indoor tanning and other consumer applications. Treatment can be based on photolysis only (i.e., mitigation primarily via direct absorption UV light) and photocatalysis (i.e., primarily via surface-based reactivity based on the catalyst absorbing the light). Photocatalysis is commonly facilitated with nanoparticulate titanium dioxide $\left(\mathrm{TiO}_{2}\right)$, a material that is considered efficient, stable, reasonably durable, and cost-efficient [22-24]. Novel materials for $\mathrm{TiO}_{2}$-based photocatalysis can improve the efficiency of photolytic UV-A treatment, as shown in the context of swine production $[1,20]$.

The photocatalysis reaction is initiated when photons of sufficient energy (more than bandgap) irradiates the $\mathrm{TiO}_{2}$ surface, resulting in electron $\left(e^{-}\right) /$hole $\left(h^{+}\right)$generation $[23,25,26]$. Activation of $\mathrm{TiO}_{2}$ occurs at wavelengths $<400 \mathrm{~nm}$ [27]. Although the detailed mechanism of photocatalysis varies with different target pollutants, it is commonly agreed that the primary reactions responsible are interfacial redox reactions of electrons and holes with adsorbed pollutants or mediators such as water [23,28,29].

Gaseous emission treatment in the barn through photocatalysis with $\mathrm{TiO}_{2}$ and UV-A light has been shown to be effective in reducing $\mathrm{NH}_{3}$, GHGs, VOCs, and odor $[1,18,19,21]$ in the context of swine production. However, it is necessary to test whether UV treatment is useful for conditions associated with the poultry barn due to the lack of previous research. In addition, recent advancements in UV, such as novel $\mathrm{TiO}_{2}$ coatings and energy-efficient UV-A lamps (i.e., light-emitting diode, LED) warrant testing of their applications to poultry housing.

This study was conducted to determine the potential for application of photocatalysis to poultry barn prior to pilot or farm-scale experiments. In other words, the objective of this study was to evaluate the UV-A treatment of $\mathrm{NH}_{3}, \mathrm{H}_{2} \mathrm{~S}$, GHGs, and $\mathrm{O}_{3}$ in simulated (lab-scale) conditions of a poultry barn. The effects of several variables were tested: (a) treatment time, (b) $\mathrm{TiO}_{2}$-based photocatalysis vs. direct photolysis, (c) light intensity (LED vs. fluorescent lamps), (c) poultry dust accumulation on photocatalyst, and (d) relative humidity, RH. Our working hypothesis was that longer treatment time, photocatalysis, LED light, and the presence of moisture, should improve the apparent treatment efficiency, while the presence of dust should not affect it. The experimental $\mathrm{NH}_{3}$ and $\mathrm{H}_{2} \mathrm{~S}$ concentrations, treatment times, and RH were selected to provide realistic conditions in poultry barns, and thus to provide useful data for UV-A treatment scaling up. The GHGs and $\mathrm{O}_{3}$ were measured for a 
preliminary assessment of the broader impact of proposed treatment on important ambient and indoor air quality parameters.

\section{Methods}

\subsection{Experimental System}

An experimental system to evaluate gas emission reduction efficacy under UV-A irradiation was based on a modified setup from previous research, Figure 1 [21,30]. Three mass flow controllers were used to control the dilution of the standard gases and pure air and the RH. A $500 \mathrm{~mL}$ glass gas sampling bulb (Supelco, Bellefonte, PA, USA) was installed before and after the UV treatment reactor. The standard gases flowing through the $200 \mathrm{~mL}$ reactor were irradiated with UV-A through a quartz window. The reactor bottom was made from an ordinary glass that was coated with a photocatalyst (nanostructured $\mathrm{TiO}_{2}$ at $10 \mu \mathrm{g} \cdot \mathrm{cm}^{-2}$ from PureTi, Cincinnati, $\mathrm{OH}, \mathrm{USA}$ ). The reactor temperature was maintained at $25 \pm 3{ }^{\circ} \mathrm{C}$ while the heat generated by the UV lamps was discharged from the UV chamber by circulating-cooling tubes connected to the isothermal water bath.

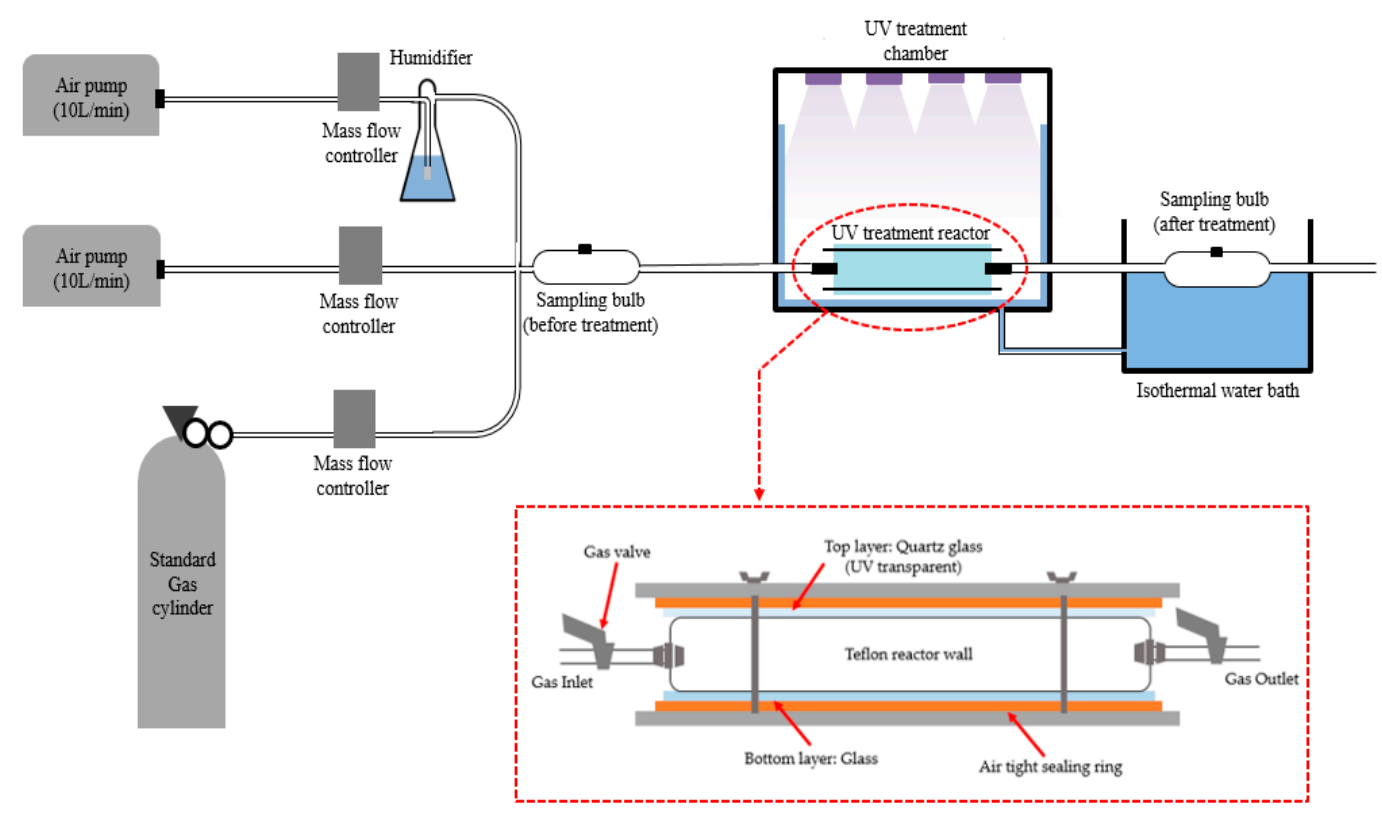

Figure 1. Schematic of UV-based mitigation of target gases at treatment times consistent with scaled-down conditions in the poultry barn.

The gas flow rate into the reactor ranged from $60-300 \mathrm{~mL} \cdot \mathrm{min}^{-1}$, resulting in a range of $40 \mathrm{~s}$ to $200 \mathrm{~s}$ treatment time. The treatment time was selected to represent typical air exchange rates inside poultry barns. $\mathrm{NH}_{3}$ standard gas (70.5 ppm in $\mathrm{N}_{2}$, ultra-high-purity, UHP, grade, Praxair, Ames, IA, USA) was diluted to $30 \mathrm{ppm}$, a typical concentration reported inside poultry barns [31-33]. Similarly, $\mathrm{H}_{2} \mathrm{~S}$ standard gas (5.2 ppm in $\mathrm{N}_{2}$, UHP grade, Praxair) was diluted to $0.5 \mathrm{ppm}$. The humidifier was used to adjust to three RH levels (approximately 0, 12\%, 40\%, and 60\%). GHGs and $\mathrm{O}_{3}$ concentrations were measured simultaneously with changes to $\mathrm{NH}_{3}$ and $\mathrm{H}_{2} \mathrm{~S}$. Because ambient air was used as a source, a certain naturally occurring level of GHG and $\mathrm{O}_{3}$ naturally exists in the background of all experiments in the absence of all treatments. Typical values of $\mathrm{NH}_{3}, \mathrm{H}_{2} \mathrm{~S}, \mathrm{CH}_{4}, \mathrm{CO}_{2}, \mathrm{~N}_{2} \mathrm{O}$, and $\mathrm{O}_{3}$ were $30 \mathrm{ppm}, 0.5 \mathrm{ppm}, 2.2 \mathrm{ppm}, 350 \mathrm{ppm}, 0.2 \mathrm{ppm}$, and $23 \mathrm{ppb}$ in the absence of any photolytic treatment, i.e., background control runs. The detection methods for each are described below. These environmental parameters were consistent with those observed in typical USA poultry and livestock production barns [34,35]. All experiments were performed in triplicate. 


\subsection{UV-A Irradiation Sources}

Fluorescent lamps (Spectroline, Westbury, NY, USA) and an LED lamp (ONCE, Plymouth, MN, USA) were used; both UV lamps have a primary wavelength of $365 \mathrm{~nm}$ (Table 1). The lamps were installed $0.20 \mathrm{~m}$ above the UV treatment reactor. The light intensity was measured at $0.20 \mathrm{~m}$ distance from the source with an ILT-1700 radiometer equipped with an NS365 filter and SED033 detector (International Light Technologies, Peabody, MA, USA). The LED had $\sim 4 \times$ greater intensity compared with the fluorescent lamp for nearly identical power consumption (measured w/ P3 wattage meter, Lexington, NY, USA).

Table 1. Comparison of UV-A lamps.

\begin{tabular}{ccc}
\hline & Fluorescent & LED \\
\hline $\begin{array}{c}\text { Total light intensity }\left(\mathrm{mW} \cdot \mathrm{cm}^{-2}\right) \\
\text { Power consumption }(\mathrm{W})\end{array}$ & 0.44 & 4.85 \\
& 48.2 & 43.3 \\
$\begin{array}{c}\text { Lamps position inside the UV } \\
\text { chamber (4 fluorescent lamps and } \\
\text { an array of 108 LED chips on an Al } \\
\text { board sources were used) }\end{array}$ & & \\
\end{tabular}

\subsection{Ammonia and Hydrogen Sulfide}

$\mathrm{NH}_{3}$ concentrations were measured in real-time using a Drager Xam 5600 portable gas analyzer (Luebeck, Germany) with $\mathrm{NH}_{3}$ sensors (range: 0-300 ppm). The Drager analyzer was calibrated using Drager calibration software and standard gases. $\mathrm{H}_{2} \mathrm{~S}$ was measured (also in real-time) using a gas monitoring system (OMS-300, Smart Control \& Sensing Inc., Daejeon, Rep. of Korea) equipped with the $\mathrm{H}_{2} \mathrm{~S} / \mathrm{C}-50$ electrochemical gas sensors from Membrapor Co. (Wallisellen, Switzerland; range: $0-50 \mathrm{ppm}$. The $\mathrm{H}_{2} \mathrm{~S}$ gas sensor was calibrated using standard gases. The flow rate used in this study was $60,300 \mathrm{~mL} \cdot \mathrm{min}^{-1}, \mathrm{NH}_{3}$, and $\mathrm{H}_{2} \mathrm{~S}$ samples were collected in $5 \mathrm{~L}$ Tedlar bags to overcome the limitations associated with the sample collection flow rates required by the portable analyzers $\left(\mathrm{NH}_{3}\right.$ : $0.5 \mathrm{~L} \cdot \mathrm{min}^{-1}$ and $\mathrm{H}_{2} \mathrm{~S}: 2 \mathrm{~L} \cdot \mathrm{min}^{-1}$ ).

\subsection{Greenhouse Gases}

GHGs samples were collected using syringes by drawing gas from the sampling bulbs and injecting them into evacuated $5.9 \mathrm{~mL}$ Exetainer vials (Labco Ltd, UK). Samples were analyzed on a gas chromatography (GC) equipped with a flame ionization detector (FID) and electron capture detector (ECD) detectors (SRI Instruments, Torrance, CA, USA). Standard calibrations were constructed daily using $10.3 \mathrm{ppm}$ and $20.5 \mathrm{ppm} \mathrm{CH}_{4} ; 1,005 \mathrm{ppm}$ and 4,010 ppm $\mathrm{CO}_{2} ; 0.101 \mathrm{ppm}$ and $1.01 \mathrm{ppm} \mathrm{N} \mathrm{N}_{2} \mathrm{O}$; and pure helium was used at 0 ppm (Air Liquide America, Plumsteadville, PA, USA) [36]. Samples were stored at $4{ }^{\circ} \mathrm{C}$ immediately after collection and analyzed within one day after sampling.

\subsection{Ozone}

A real-time $\mathrm{O}_{3}$ detector (Gas Sensing, Hull, IA, USA) was connected to the monitoring system (Series 500 monitor, Aeroqual, New Zealand) and installed in the UV treatment chamber. The $\mathrm{O}_{3}$ concentration was analyzed by measuring the concentration of $\mathrm{O}_{3}$ collected in a $0.5 \mathrm{~L}$ glass gas sampling bulb connected downstream from the UV reactor. The sensor was factory-calibrated before use. The detection range was from $0-0.05 \mathrm{ppm}$. 


\subsection{Dust Collection in A Poultry Barn}

The presence of accumulated dust could potentially compromise the effectiveness of photocatalyst. Thus, in order to evaluate the effect of dust on mitigation efficiency, dust was collected at Poultry Teaching Farm (Ames, IA, USA). Three Styrofoam boxes that held two glass plates (blank and coated with $\mathrm{TiO}_{2}$ ) were placed inside the barn horizontally and accumulated dust over time (Figure 2, part a). Also, three aluminum (Al) foil coupons were attached to simultaneously measure the weight of accumulated dust per area. The Styrofoam boxes were then removed from the barn, one by one, at one-week intervals for three weeks. Then, the same glass plates were mounted into the UV reactor (as the 'Bottom layer: Glass in Figure 1) for testing. The weight of accumulated dust was estimated by subtracting the final from the initial $\mathrm{Al}$ foil coupon weight and extrapolated to the entire bottom layer glass area of the reactor. In addition, the effect of accumulated dust on light absorption at the glass with and without $\mathrm{TiO}_{2}$ was measured using a 300-lumen bulb and a radiometer equipped with an XRD340B detector (International Light Technologies, Peabody, MA, USA), Figure 2 (part b).

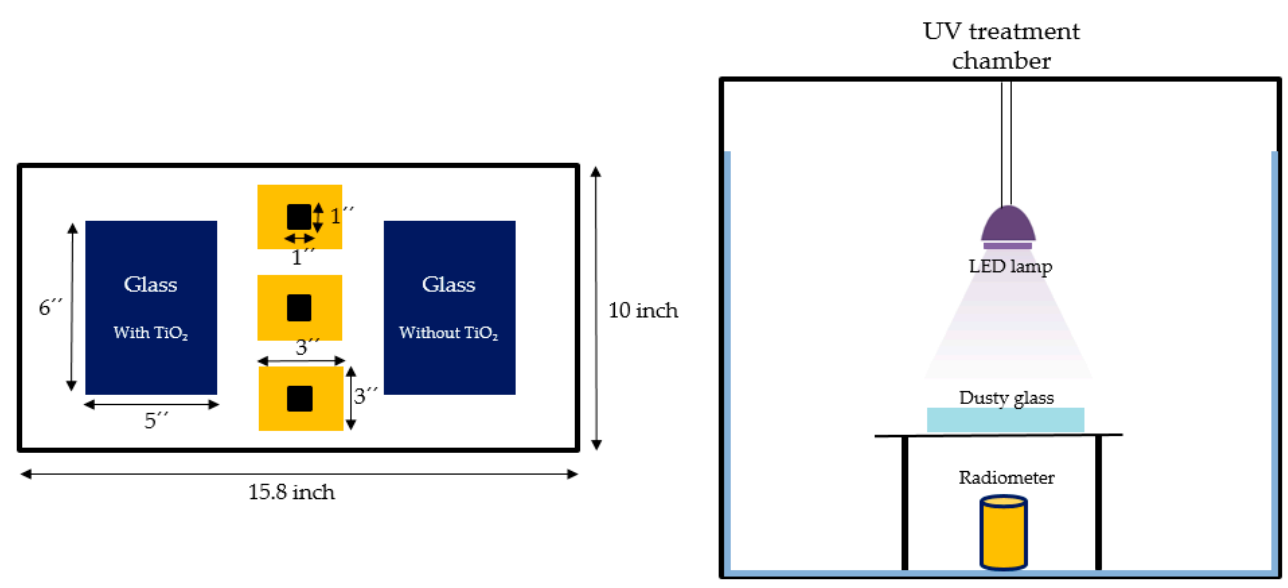

(a)

(b)

Figure 2. Investigation of the effect of accumulated poultry dust on photocatalysis. (a) Dust collection box; (b) Schematic of the method used for measuring the light absorption by the accumulated dust on the glass (i.e., the bottom layer of the reactor in Figure 1) with and without $\mathrm{TiO}_{2}$.

\subsection{Data analysis, Accounting for Sample Losses Due to Adsorption}

Gas samples were collected after a $1 \mathrm{~h}$ of equilibration time under each treatment condition. Small, yet consistent losses to target gases were observed over the course of experiments with the photocatalyst. Thus, the standard gas recoveries were also measured and reported as 'adsorption' series in the Results. The adsorption to the photocatalyst was assumed to be responsible for the losses and accounted for in the analyses. The overall mean reduction for each measured gas was estimated using:

$$
\% \text { Reduction }=\frac{C_{\text {Con }}-C_{\text {Treat }}}{C_{\text {Con }}} \times 100 \%
$$

where: $C_{C o n}$ and $C_{\text {Treat }}$ are the mean measured concentrations in control and treated air, respectively.

\subsection{Statistical Analysis}

The R program (version 3.4.2) was used to analyze the effects of the catalyst, lamp-type, and environmental parameters on the reduction of the target gases by one way ANOVA. This statistical analysis generated $p$-values for evaluating whether a specific parameter/factor had a significant influence on treatment. A significant difference was defined for a $p$-value $<0.05$. 


\section{Results}

\subsection{Ammonia}

In general, longer treatment time, use of photocatalyst, increased light intensity, and the presence of moisture in treated air improved the $\% \mathrm{NH}_{3}$ reduction. The highest reduction was $18.7 \%$ for $200 \mathrm{~s}$ treatment, LED photocatalysis at $12 \% \mathrm{RH}$, and no dust conditions. Dust decreased the performance of the photocatalyst. Detailed summaries and statistical significance of the effects of each treatment are presented in the subsections below.

\subsubsection{Effect of the Photocatalyst, Relative Humidity, Light Intensity, and Treatment Time}

The controlled $\mathrm{NH}_{3}$ concentration used in the control group using the standard gas was $29.8 \pm 1.2 \mathrm{ppm}$. Figure 3 illustrates the $\mathrm{NH}_{3}$ reduction at three treatment conditions (direct photolysis, photocatalysis, and adsorption $\left(\right.$ by $\mathrm{TiO}_{2}$ )) under different $\mathrm{RH}$, and $40 \mathrm{~s}$ (part a) and $200 \mathrm{~s}$ (part b) treatment time, respectively. Photocatalysis resulted in a 2.6-18.7\% reduction, which was statistically significant for nearly all conditions (Tables A1 and A2, Appendix A). In comparison, direct photolysis resulted in no treatment or negligible \% reduction and was not statistically significant.

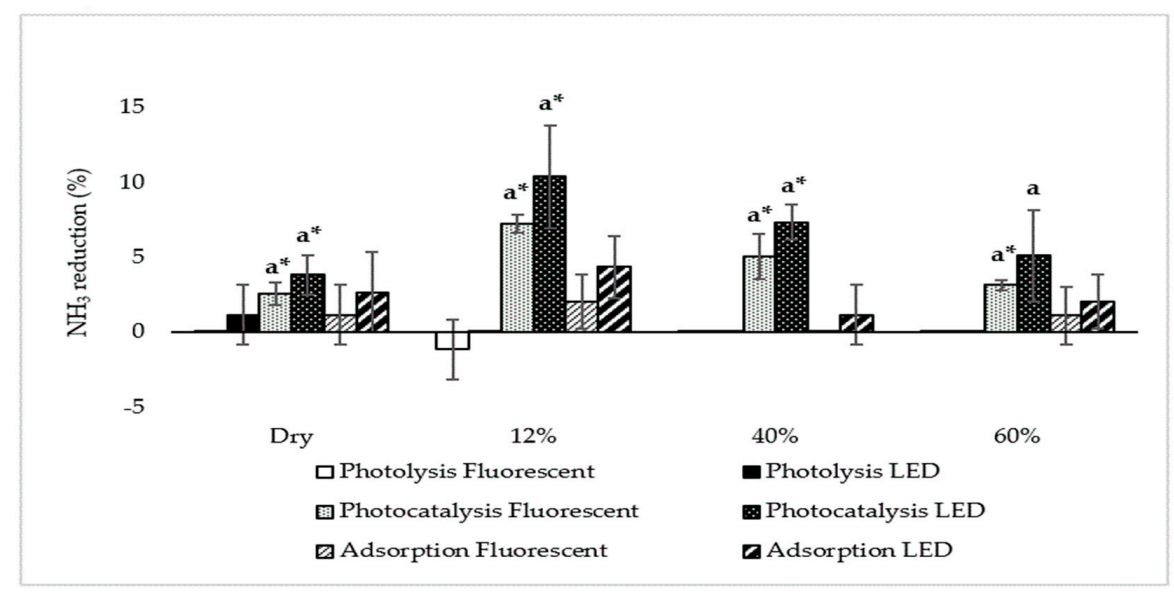

(a)

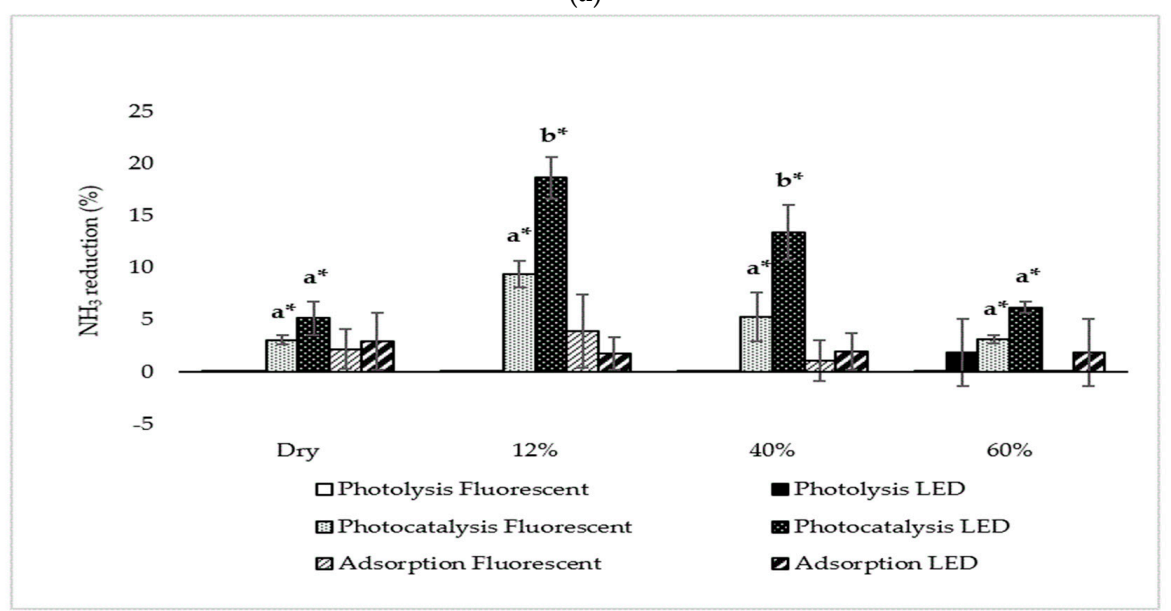

(b)

Figure 3. Comparison of $\mathrm{NH}_{3}$ mitigation under different treatment types and light intensities. (a) \% reduction at treatment time of $40 \mathrm{~s}$; (b) \% reduction at treatment time of $200 \mathrm{~s}$; Superscript $\left({ }^{*}\right)$ signifies a statistical difference compared to the control $(p<0.05)$, and the different characters $(a, b)$ signify statistical difference when comparing different light intensities (fluorescent vs. LED) at the same relative humidity $(p<0.05)$. The $\%$ reduction was the highest at $12 \%(7.3-18.7 \%, p<0.05)$. Error bars signify \pm standard deviation. 
Closer inspection of the patterns in the effectiveness of photocatalysis showed that it was affected by $\mathrm{RH}$, light (type) intensity, and treatment time. The LED lamp (having $\sim 4 \times$ higher intensity) facilitated a higher \% reduction, the greatest $(\sim 2 \times)$ improvement observed at $12 \% \mathrm{RH}$. Moreover, the statistical difference in this improvement was shown for both $\mathrm{RH} 12 \%$ and $40 \%$ at $200 \mathrm{~s}$ treatment (Figure 3 , part b).

Figure 4 highlights the \% reduction with different treatment times and RH. The LED-based photocatalysis at lower RH (12\% and 40\%) outperformed the fluorescent-based treatment for $\mathrm{NH}_{3}$ mitigation.

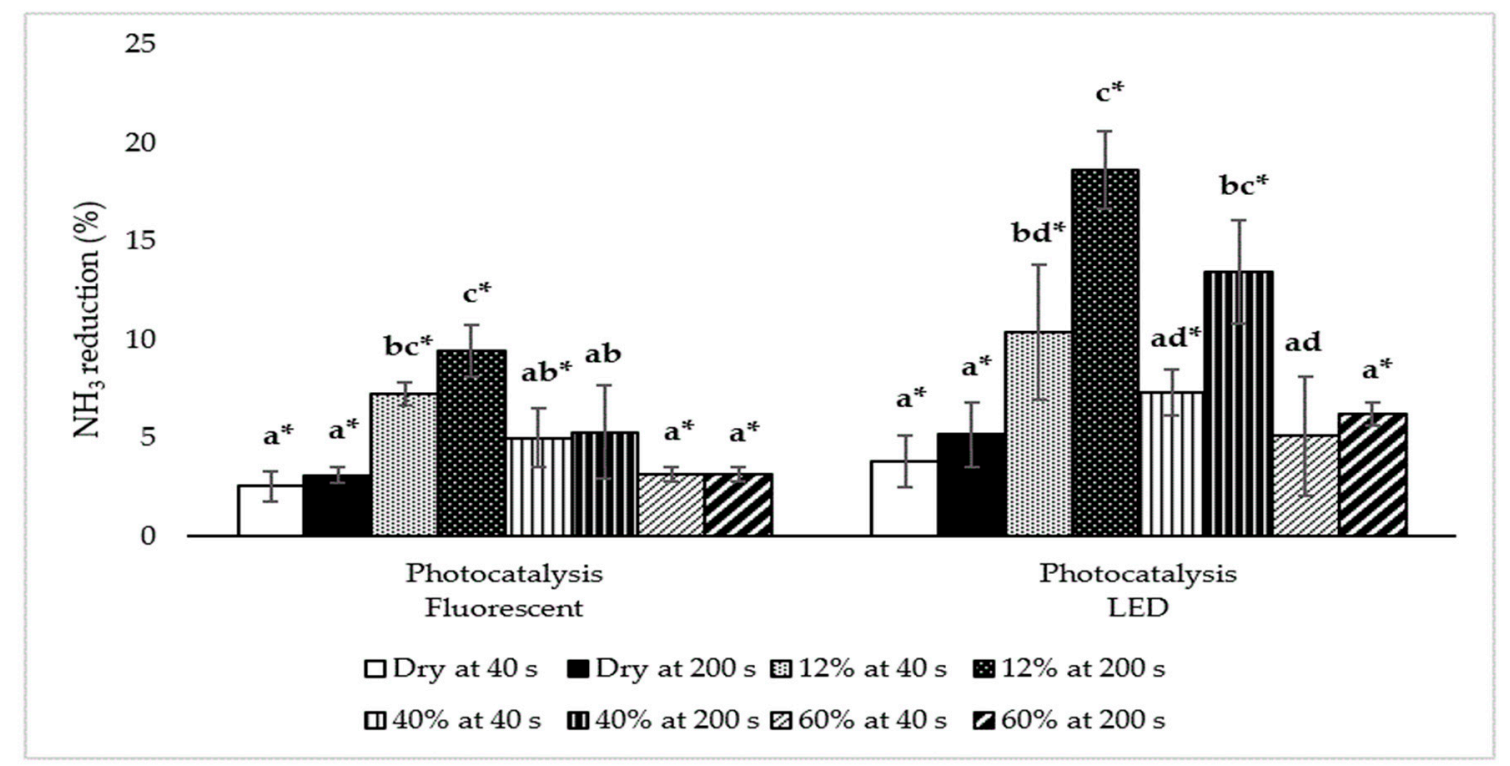

Figure 4. Comparison of $\mathrm{NH}_{3}$ mitigation under different relative humidity and treatment time. Superscript $\left(^{*}\right)$ signifies a statistical difference compared to the control $(p<0.05)$, and the different characters $(a, b, c, d)$ signify the statistical difference between treatments associated with one UV lamp type $(p<0.05)$. Error bars signify \pm standard deviation.

\subsubsection{Effect of Poultry Dust}

Dust accumulation on $\mathrm{TiO}_{2}$ had a detrimental effect on the effectiveness of photocatalysis (Figure 5, Tables A3 and A4), particularly at low RH (12\%). In addition, accumulated poultry dust absorbed light, and the linear increase (from 14.1 to 40.1\%) in light absorption with dust accumulation on the photocatalyst surface over time (from 6.9 to $16.3 \mathrm{mg} \cdot \mathrm{cm}^{-2}$ ) was observed. The average light absorption was $27 \pm 12 \%$, and the dust accumulation was $11 \pm 4 \mathrm{mg} \cdot \mathrm{cm}^{-2}$ (Table 2).

Table 2. Light absorption by accumulated dust and weight of accumulated poultry dust on $\mathrm{TiO}_{2}$.

\begin{tabular}{ccc}
\hline Dust Accumulation Duration & Light Absorption (\%) & Dust Accumulation $\left(\mathbf{m g} \cdot \mathbf{c m}^{\mathbf{- 2}}\right)$ \\
\hline 1 week & $14.1 \pm 3.6$ & $6.9 \pm 0.4$ \\
2 weeks & $27.1 \pm 4.0$ & $11.0 \pm 0.7$ \\
3 weeks & $40.1 \pm 5.9$ & $16.3 \pm 1.3$ \\
Average & $27.1 \pm 12$ & $11.4 \pm 4.2$ \\
\hline
\end{tabular}

The values in the table report the mean \pm standard deviation. 


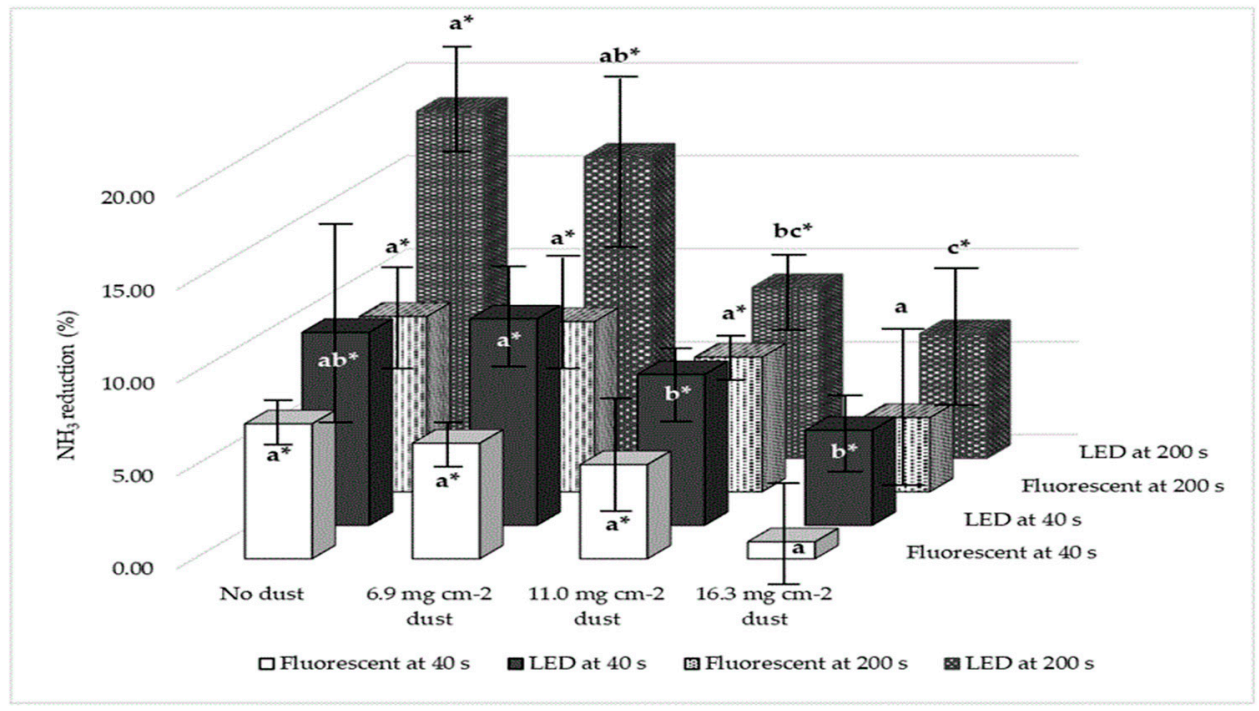

(a)

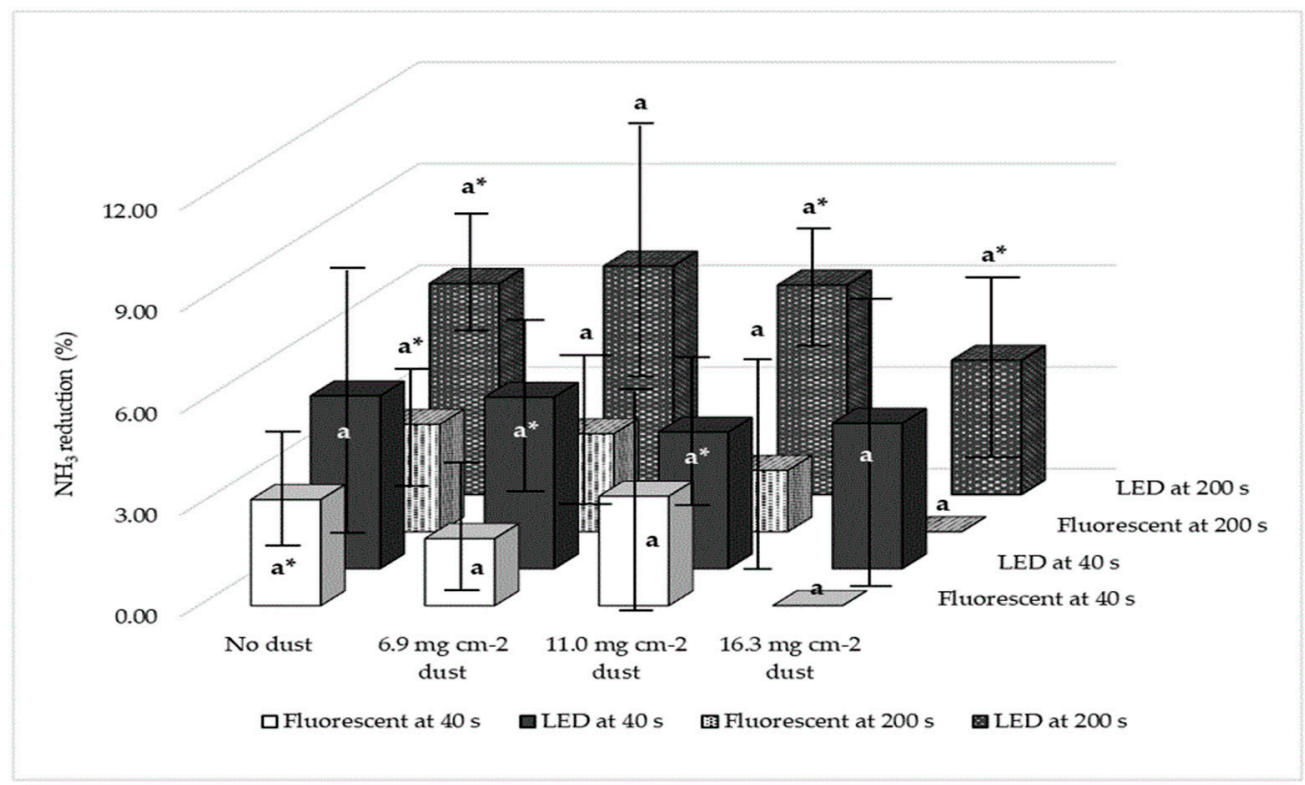

(b)

Figure 5. Comparison of $\mathrm{NH}_{3}$ mitigation under different poultry dust levels. (a) \% reduction at relative humidity of $12 \%$; (b) \% reduction at relative humidity of $60 \%$; Superscript ${ }^{*}$ ) signifies a statistical difference compared to the control $(p<0.05)$, and the different characters $(a, b, c)$ signify statistical difference at the same treatment time and the same light intensity $(p<0.05)$. Error bars signify \pm standard deviation.

There was no statistical significance of the change in the reduction at RH 60\% (Figure 5, part b). The low (12\%) RH had the most considerable decrease in mitigation (from 18.7\% to 5.1\%) under the LED light, yet it was still statistically significant even with the highest dust accumulation of $16.3 \mathrm{mg} \cdot \mathrm{cm}^{-2}$ $(p<0.05)$. In other words, the LED-based treatment was still performing well, regardless of dust accumulation $(p<0.05)$. 


\subsection{Hydrogen Sulfide}

The controlled $\mathrm{H}_{2} \mathrm{~S}$ concentration in the control group using the standard gas was $0.52 \pm 0.02 \mathrm{ppm}$. No statistically significant reduction in $\mathrm{H}_{2} \mathrm{~S}$ concentration was observed under any experimental conditions $(p>0.05)$, even with the most favorable conditions of $200 \mathrm{~s}$, photocatalyst usage, LED irradiation, and elevated moisture (Figure 6). Similarly, there was no statistical difference associated with the dust accumulation at $12 \% \mathrm{RH}$ regardless of the light type (intensity) and treatment time (Figure 7).

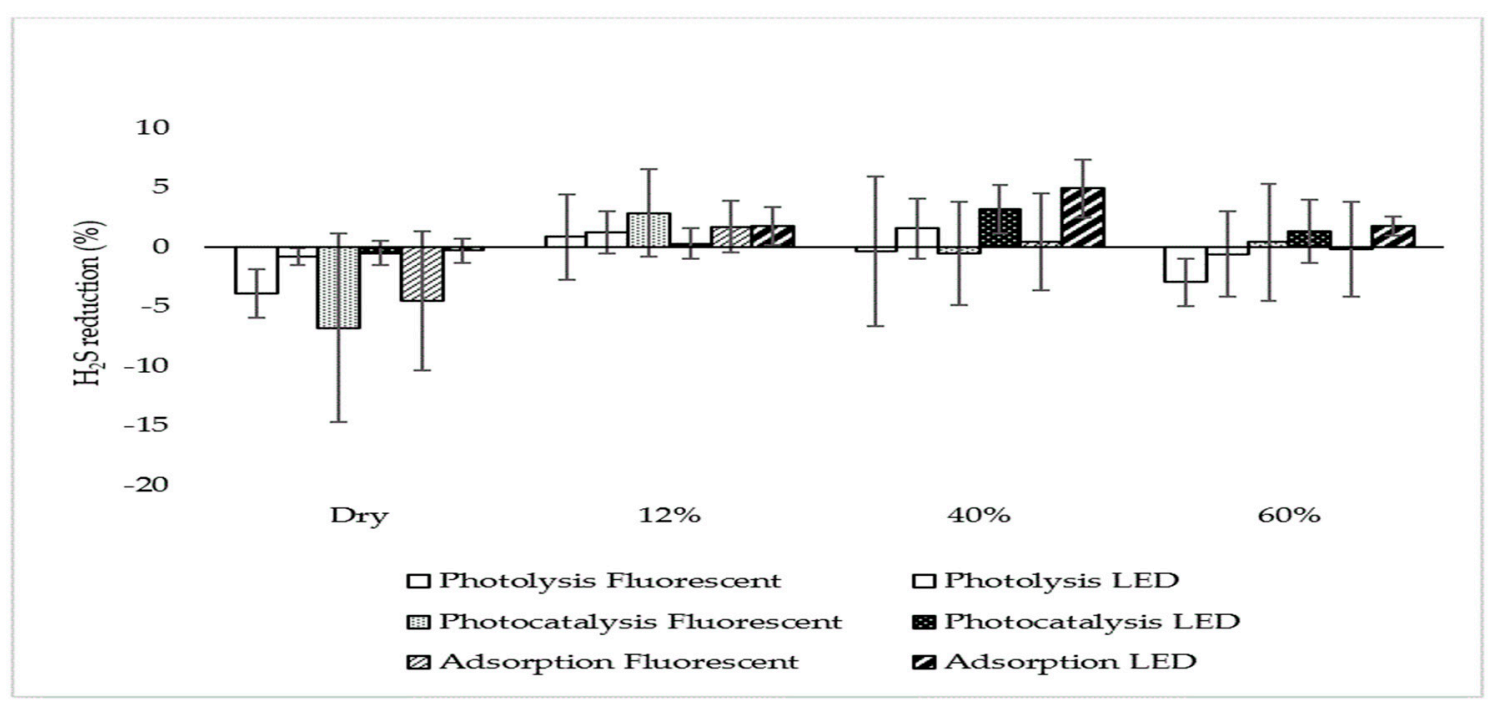

(a)

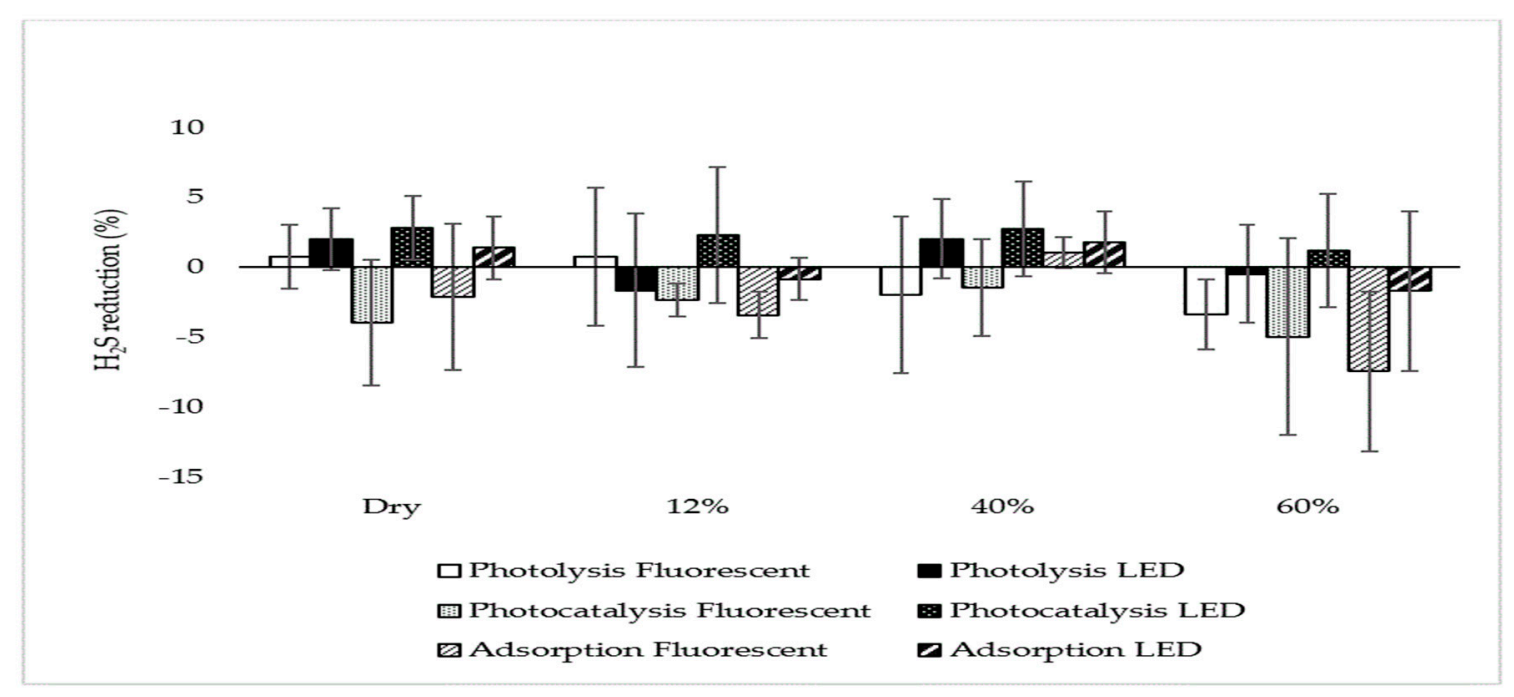

(b)

Figure 6. Comparison of $\mathrm{H}_{2} \mathrm{~S}$ mitigation under relative humidity. (a) \% reduction at a treatment time of $40 \mathrm{~s} ;(\mathbf{b}) \%$ reduction at a treatment time of $200 \mathrm{~s}$. Error bars signify \pm standard deviation. 


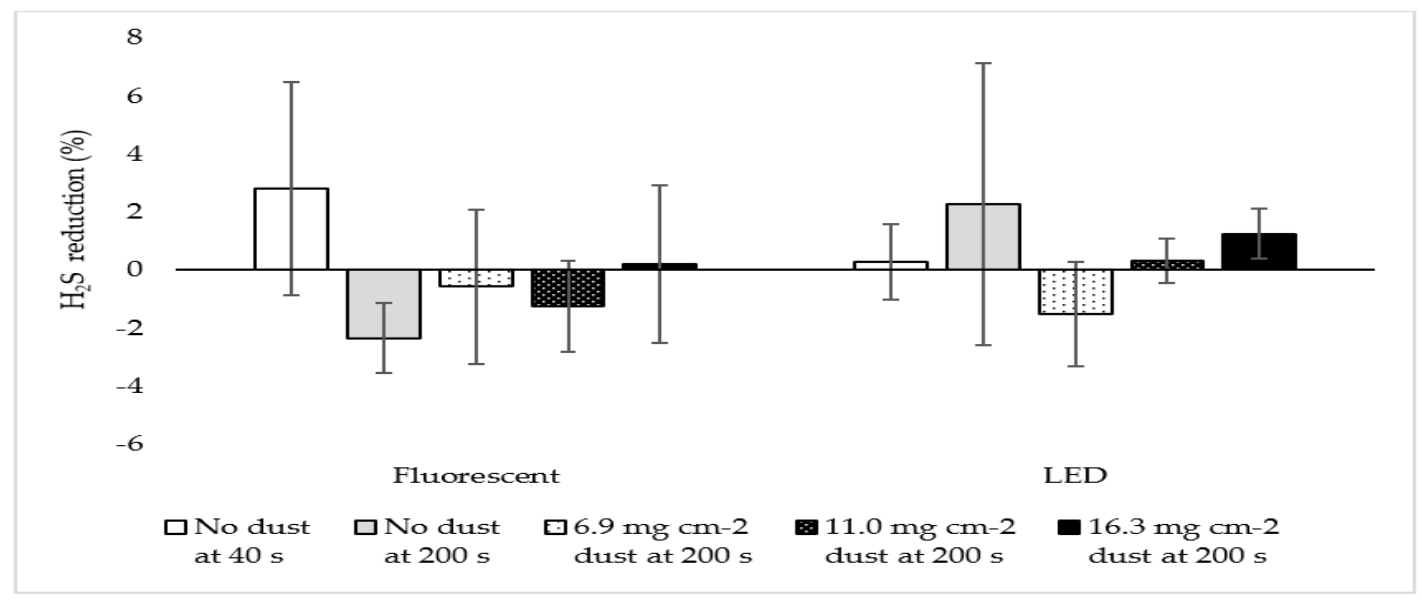

Figure 7. $\mathrm{H}_{2} \mathrm{~S}$ mitigation under different poultry dust levels at $12 \%$ of relative humidity in photocatalysis. Error bars signify \pm standard deviation.

\subsection{Greenhouse Gases}

The treatment of target gases $\left(\mathrm{NH}_{3}, \mathrm{H}_{2} \mathrm{~S}\right)$ was evaluated for a potential impact on important ambient air quality parameters, the possibility of simultaneously mitigating or generating GHGs. No GHGs were fed into the reactor; however, as noted previously, the air source naturally contained measurable amounts of these compounds. Thus, the GHGs concentrations in the treatment and control were compared.

\subsubsection{Methane}

The average concentration in controls was $2.2 \pm 0.1 \mathrm{ppm}$. There was no statistically significant change in $\mathrm{CH}_{4}$ concentration under direct photolysis, photocatalysis, and adsorption to the catalyst. Moreover, there were no statistically significant changes, regardless of $\mathrm{RH}$, light type (intensity), treatment time, and dust accumulation when $\mathrm{NH}_{3}$ and $\mathrm{H}_{2} \mathrm{~S}$ standard gases were treated with $\mathrm{UV}$ (Figures 8 and 9).

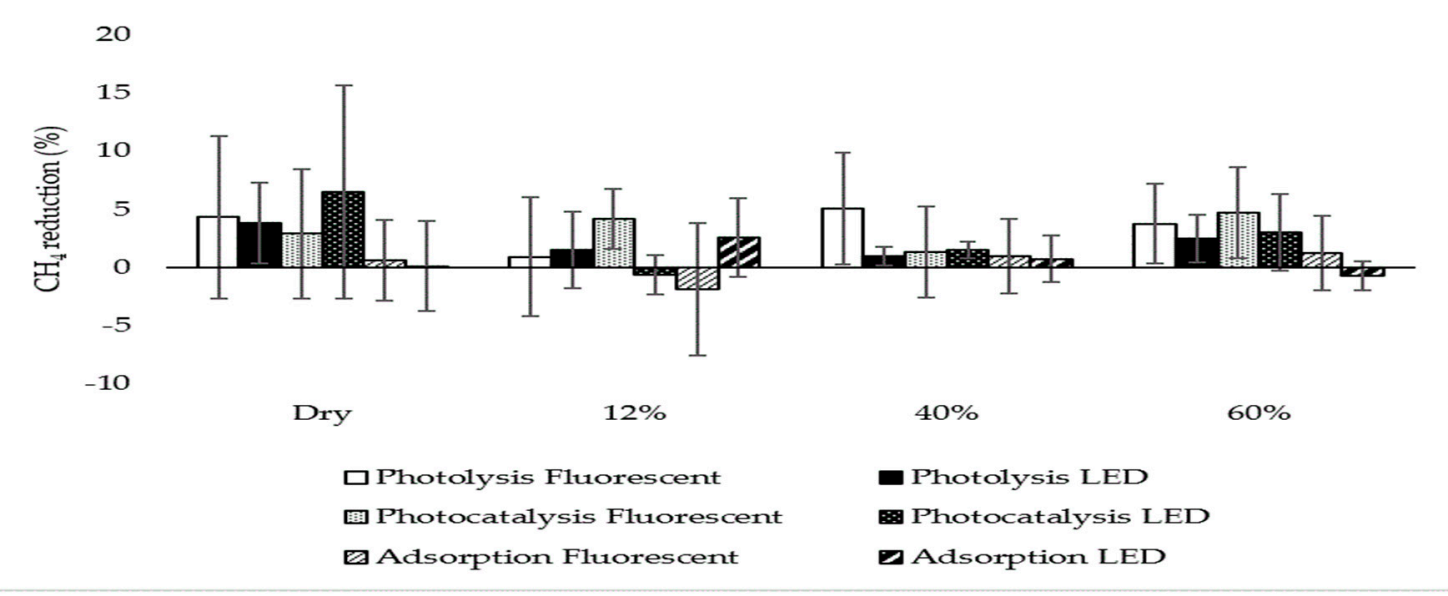

(a)

Figure 8. Cont. 


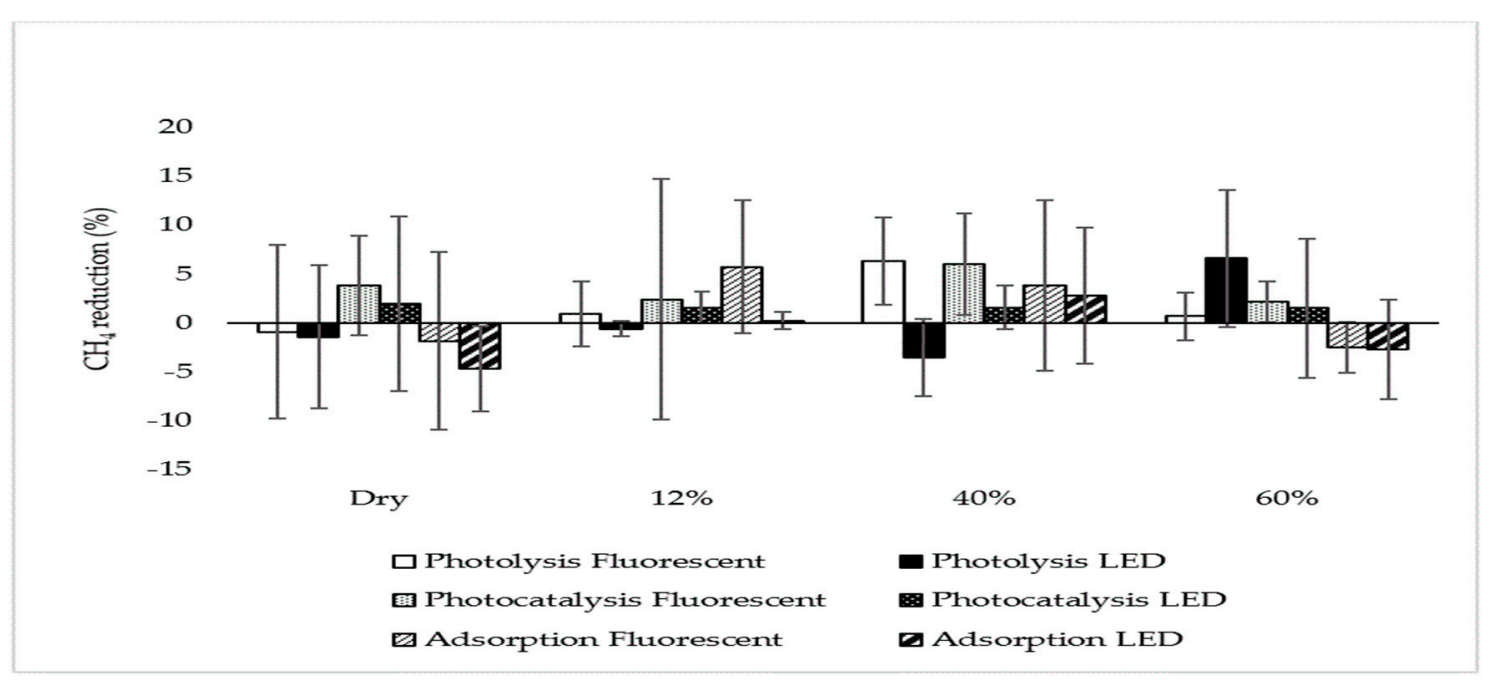

(b)

Figure 8. Comparison of $\mathrm{CH}_{4}$ mitigation under relative humidity. (a) \% reduction at a treatment time of $40 \mathrm{~s}$; (b) \% reduction at a treatment time of $200 \mathrm{~s}$. Error bars signify \pm standard deviation.

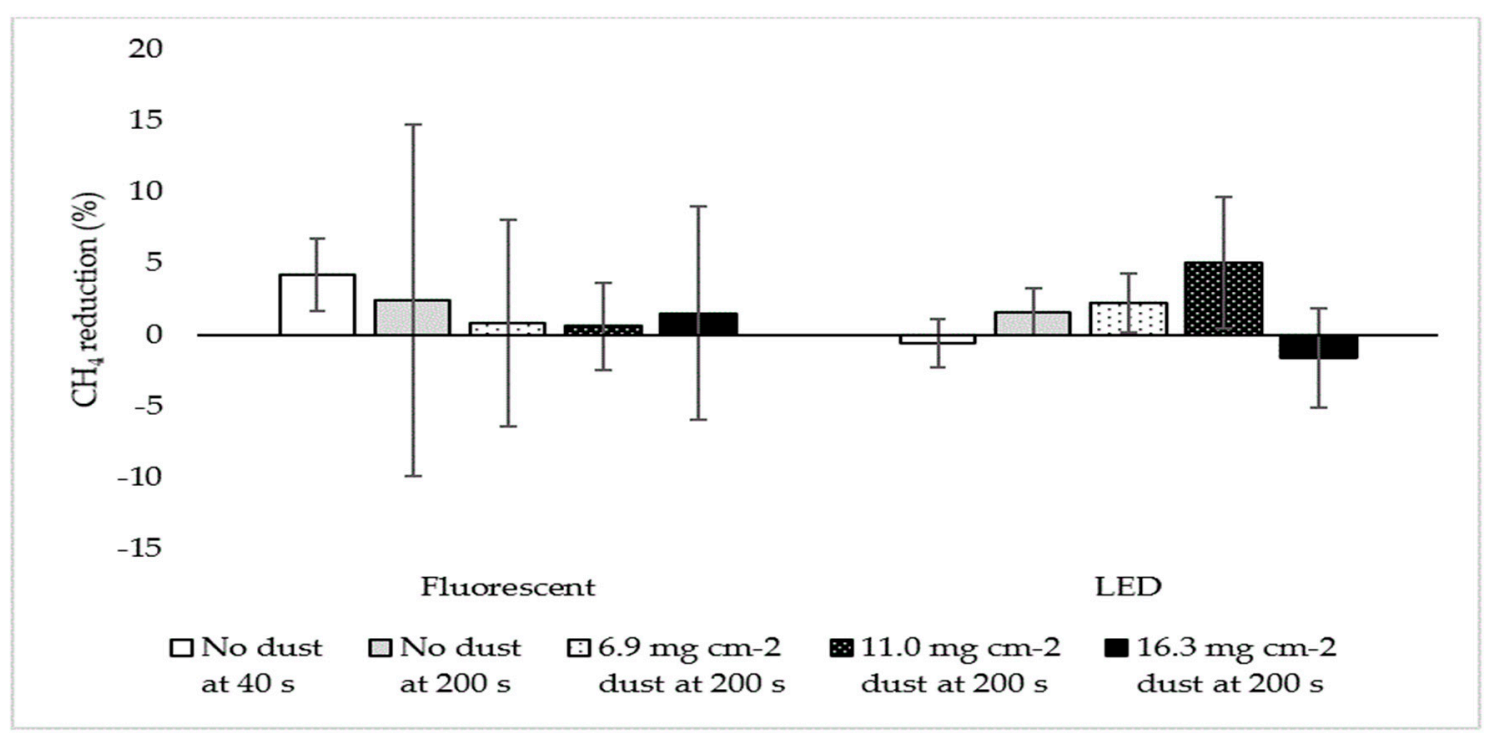

Figure 9. $\mathrm{CH}_{4}$ mitigation under different poultry dust levels at $12 \%$ relative humidity in photocatalysis. Error bars signify \pm standard deviation.

\subsubsection{Carbon Dioxide}

The average $\mathrm{CO}_{2}$ concentration in control samples (i.e., present naturally in air) was $350 \pm 25 \mathrm{ppm}$, and no mitigation was observed under photolysis and adsorption. Interestingly, there was a 3.8\% (mean) reduction at $200 \mathrm{~s}$ photocatalysis with LED at 12\% RH (Figure 10 and Table A5). Specifically, the mitigation was $3.2 \%$ and $4.4 \%$ when $\mathrm{NH}_{3}$ and $\mathrm{H}_{2} \mathrm{~S}$ standard gases were treated, respectively. However, there was no statistical difference between the two standard gases $(p>0.05)$. There was no $\mathrm{CO}_{2}$ reduction under dust accumulation (Figure 11). 


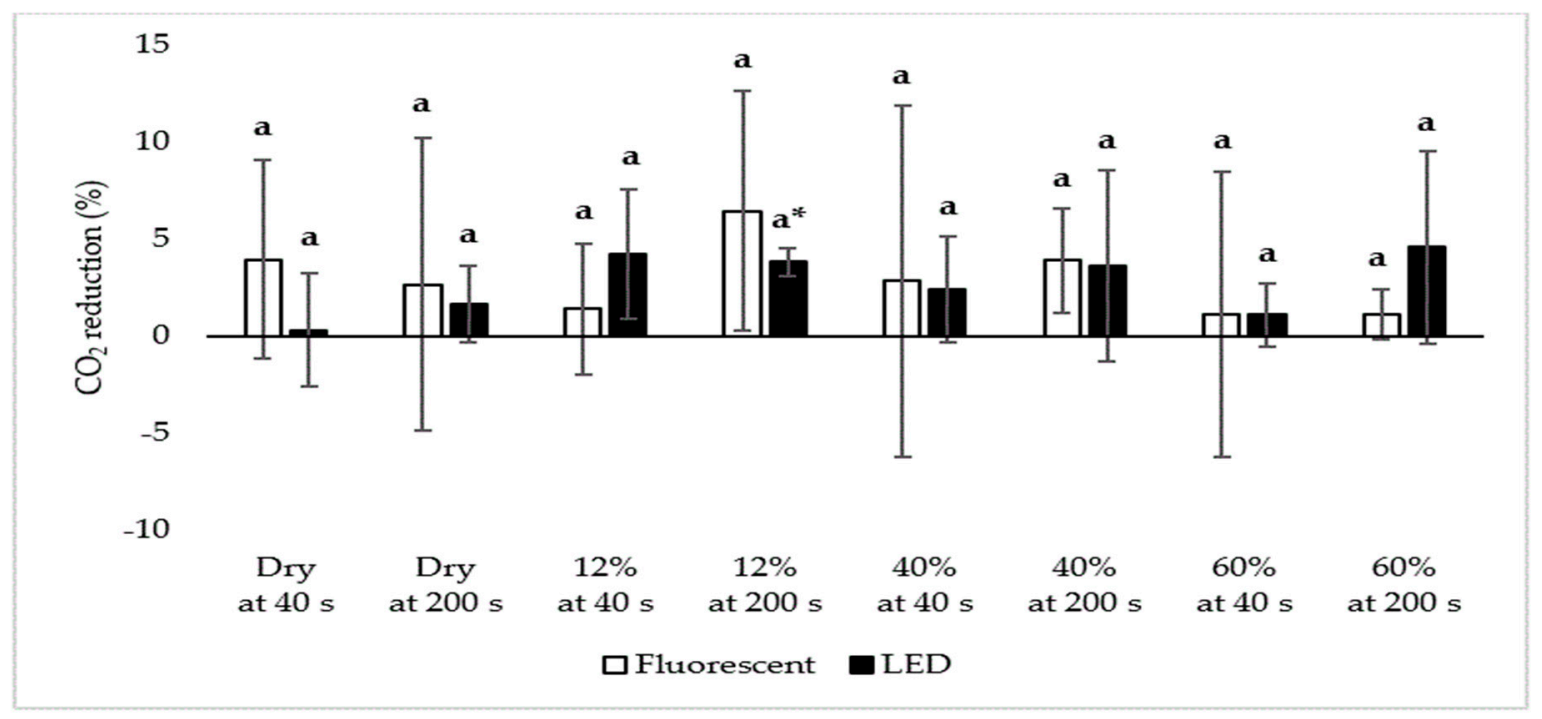

Figure 10. $\mathrm{CO}_{2}$ mitigation under different light intensity, treatment time, and relative humidity in photocatalysis. Superscript ${ }^{*}$ ) signifies a statistical difference compared to the control $(p<0.05)$, and the character (a) signifies there is no statistical difference under the two different treatment times $(p>0.05)$. Error bars singify \pm standard deviation.

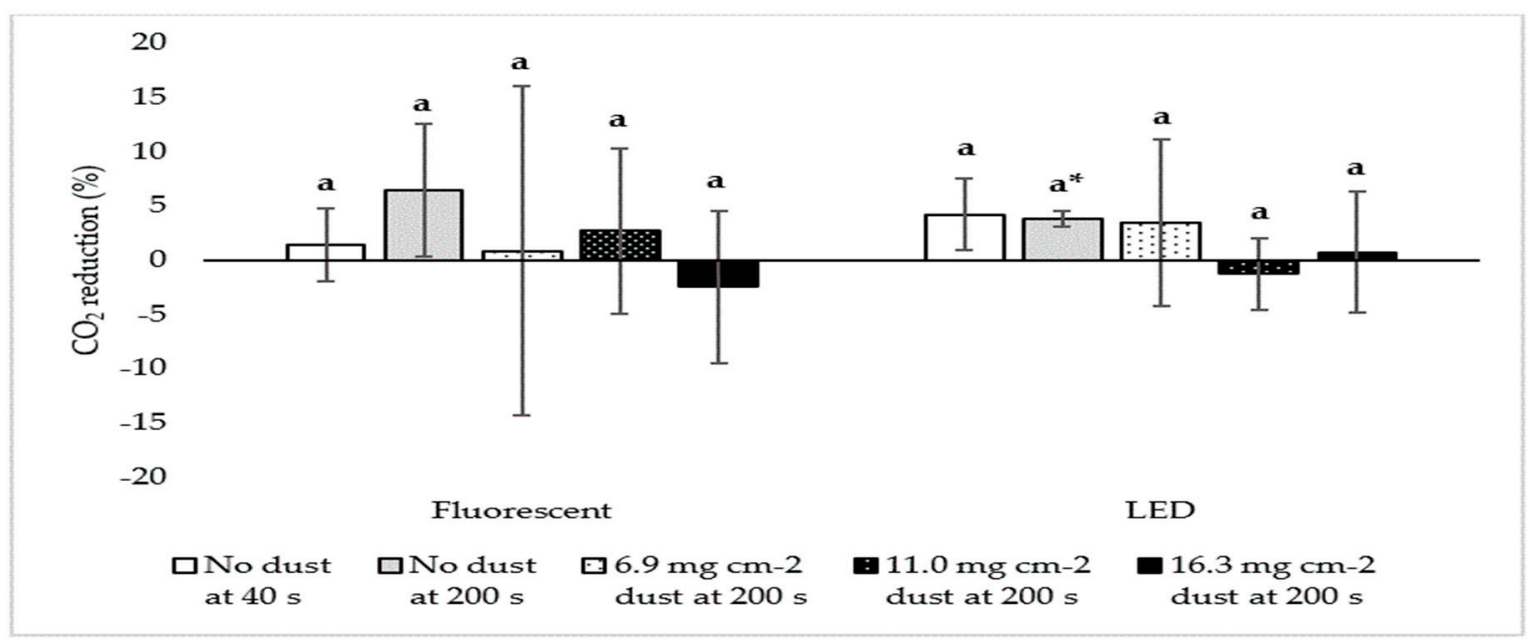

Figure 11. $\mathrm{CO}_{2}$ mitigation under different poultry dust levels at $12 \%$ of relative humidity in photocatalysis. Superscript $\left(^{*}\right)$ signifies a statistical difference compared to the control $(p<0.05)$, and the character (a) signifies there is no statistical difference under the two different treatment times $(p>0.05)$. Error bars signify \pm standard deviation.

\subsubsection{Nitrous Oxide}

In general, mitigation of concentration was observed under both direct photolysis and photocatalysis, with greater reductions with $\mathrm{TiO}_{2}$ photocatalysts. However, there was no statistical difference between the two conditions. There was no apparent relationship between $\mathrm{N}_{2} \mathrm{O} \%$ reduction and other controlled parameters.

\section{Comparison of $\mathrm{N}_{2} \mathrm{O}$ Mitigation when Treating $\mathrm{NH}_{3}$ and $\mathrm{H}_{2} \mathrm{~S}$ Standard Gas}

The average $\mathrm{N}_{2} \mathrm{O}$ concentration in control was $0.24 \pm 0.03 \mathrm{ppm}$. As much as $6.9 \%$ and $12.2 \%$ of the statistically-significant \% reduction were observed for $200 \mathrm{~s}$ photocatalysis with LED at $12 \% \mathrm{RH}$ when $\mathrm{NH}_{3}$ and $\mathrm{H}_{2} \mathrm{~S}$ were treated, respectively (Table 3). In general, statistically-significant \% reductions were found for more experimental conditions for $\mathrm{H}_{2} \mathrm{~S}$ than $\mathrm{NH}_{3}$. However, there was no significant 
difference between the $\%$ reduction resulting from the use of two standard gas treatments (i.e., $p$-values in Table 3).

Table 3. The mitigation of $\mathrm{N}_{2} \mathrm{O}$ during photocatalysis of $\mathrm{NH}_{3}$ and $\mathrm{H}_{2} \mathrm{~S}$ standard gases.

\begin{tabular}{|c|c|c|c|c|c|c|c|}
\hline \multirow{3}{*}{$\begin{array}{l}\text { Relative } \\
\text { Humidity }\end{array}$} & \multirow{3}{*}{$\begin{array}{l}\text { Type of } \\
\text { UV Lamp }\end{array}$} & \multicolumn{3}{|c|}{40 s Treatment Time } & \multicolumn{3}{|c|}{200 s Treatment Time } \\
\hline & & \multicolumn{2}{|c|}{ Standard Gas } & \multirow{2}{*}{$p$-Value ${ }^{1}$} & \multicolumn{2}{|c|}{ Standard Gas } & \multirow{2}{*}{$p$-Value ${ }^{1}$} \\
\hline & & $\mathrm{NH}_{3}$ & $\mathrm{H}_{2} \mathrm{~S}$ & & $\mathrm{NH}_{3}$ & $\mathrm{H}_{2} \mathrm{~S}$ & \\
\hline \multirow{2}{*}{ Dry } & Fluorescent & $4.1 \pm 8.2$ & $5.6 \pm 1.3$ & 0.83 & $2.7 \pm 1.7$ & $4.6 \pm 0.0 *$ & 0.36 \\
\hline & LED & $5.1 \pm 3.2$ & $7.9 \pm 0.5^{*}$ & 0.95 & $4.2 \pm 0.0$ * & $5.9 \pm 0.2 *$ & 0.49 \\
\hline \multirow{2}{*}{$12 \%$} & Fluorescent & $3.0 \pm 4.1$ & $3.1 \pm 2.8$ & 0.44 & $1.8 \pm 2.1$ & $4.8 \pm 0.4^{*}$ & 0.69 \\
\hline & LED & $6.2 \pm 4.0$ & $11.7 \pm 5.9$ & 0.09 & $6.8 \pm 1.6^{*}$ & $12.2 \pm 1.0 *$ & 0.05 \\
\hline \multirow{2}{*}{$40 \%$} & Fluorescent & $3.4 \pm 0.3^{*}$ & $3.3 \pm 0.1 *$ & 0.53 & $1.5 \pm 1.0$ & $4.5 \pm 2.3$ & 0.49 \\
\hline & LED & $5.5 \pm 1.1 *$ & $6.8 \pm 1.7^{*}$ & 0.33 & $8.6 \pm 3.1$ & $11.6 \pm 8.9$ & 0.09 \\
\hline \multirow{2}{*}{$60 \%$} & Fluorescent & $2.4 \pm 0.6$ & $3.3 \pm 0.5^{*}$ & 0.94 & $5.8 \pm 6.5$ & $5.4 \pm 0.3$ & 0.12 \\
\hline & LED & $4.0 \pm 1.8$ & $6.3 \pm 5.1$ & 0.85 & $5.3 \pm 1.4$ & $4.7 \pm 0.5^{*}$ & 0.78 \\
\hline
\end{tabular}

The value in the table reports the mean \pm standard deviation. Superscript $\left({ }^{1}\right)$ signifies value from the statistical analysis of the $\mathrm{N}_{2} \mathrm{O}$ concentrations reduced under the two standard gases. Superscript $\left(^{*}\right)$ signifies a statistical difference compared to the control $(p<0.05)$.

Effect of Photocatalyst, Light Type, Relative Humidity, Dust, and Treatment Time on $\mathrm{N}_{2} \mathrm{O}$

We further investigated the apparent mitigation of $\mathrm{N}_{2} \mathrm{O}$ (a potent GHGs) by averaging the results for $\mathrm{H}_{2} \mathrm{~S}$ and $\mathrm{NH}_{3}$ to elucidate possible mechanisms responsible for this finding. The statistically significant mitigation was observed in both direct photolysis and photocatalysis, at $3.3-6.5 \%$ and 2.8-9.5\%, respectively (Figure 12, Tables A6 and A7). In general, photocatalysis was more effective for reducing $\mathrm{N}_{2} \mathrm{O}$ than photolysis alone (Figure 12, parts a and b, Tables A6 and A7). However, there was no statistical difference between the two treatments (i.e., at dry and $12 \% \mathrm{RH}$, Table A7) were compared. Similarly, no apparent statistical significance was found for variation of the treatment time, dust accumulation, lamp type, and RH (Figures 13 and 14, Tables A8-A10). This is because there are few statistically significant \% reduction of $\mathrm{N}_{2} \mathrm{O}$ for variable parameters, without any apparent trend.

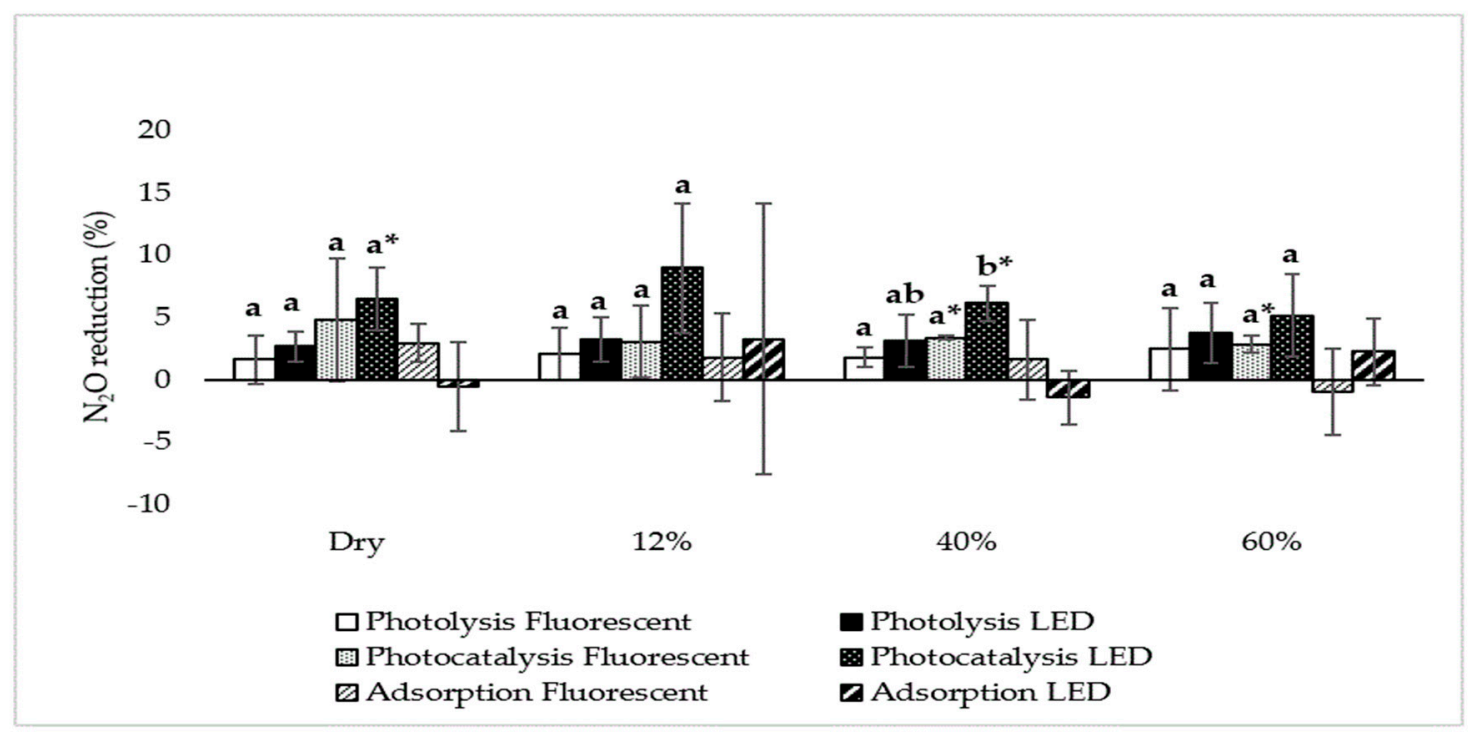

(a)

Figure 12. Cont. 


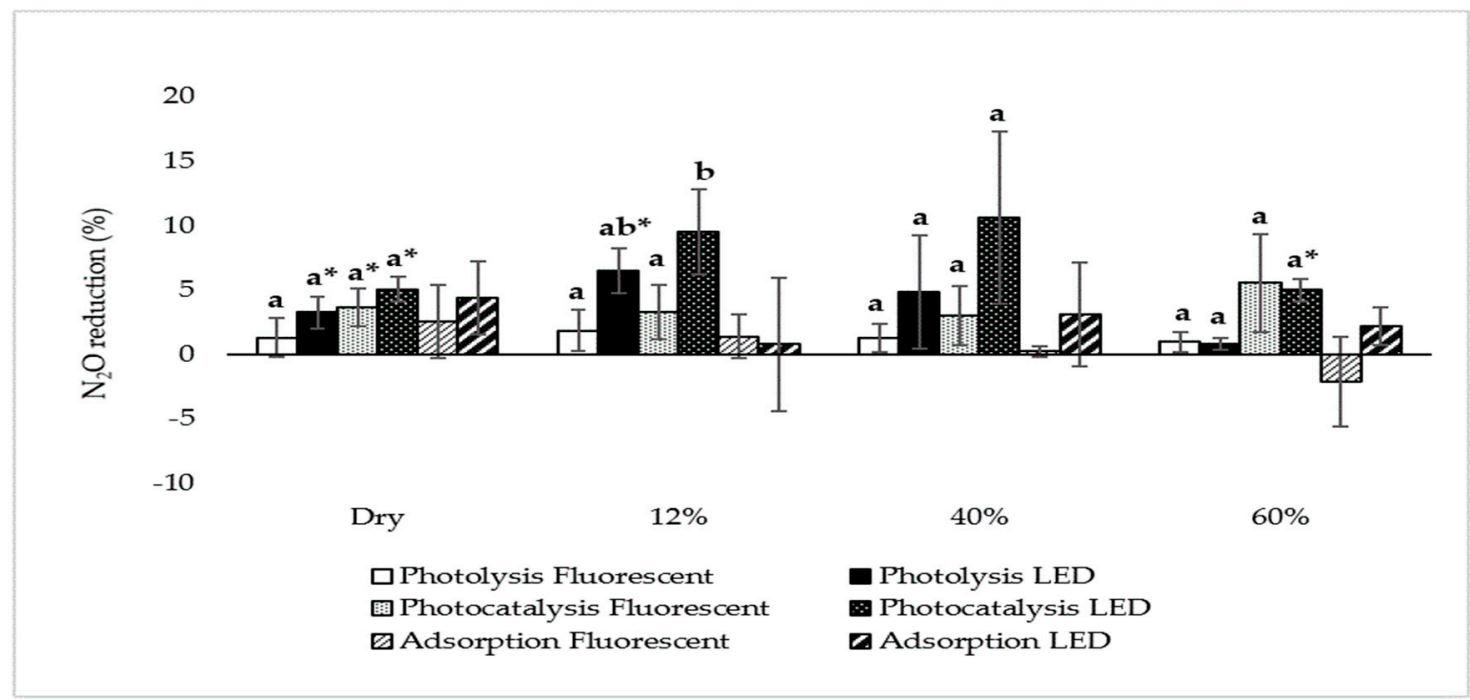

(b)

Figure 12. Comparison of $\mathrm{N}_{2} \mathrm{O}$ mitigation under different treatment types and light type intensity. (a) \% reduction at treatment time of $40 \mathrm{~s}$; (b) \% reduction at treatment time of $200 \mathrm{~s}$; Superscript $\left(^{*}\right)$ signifies a statistical difference compared to the control $(p<0.05)$, and the different characters $(a, b)$ signify statistical difference when comparing different light intensities (fluorescent vs. LED) at the same relative humidity $(p<0.05)$. Error bars signify \pm standard deviation.

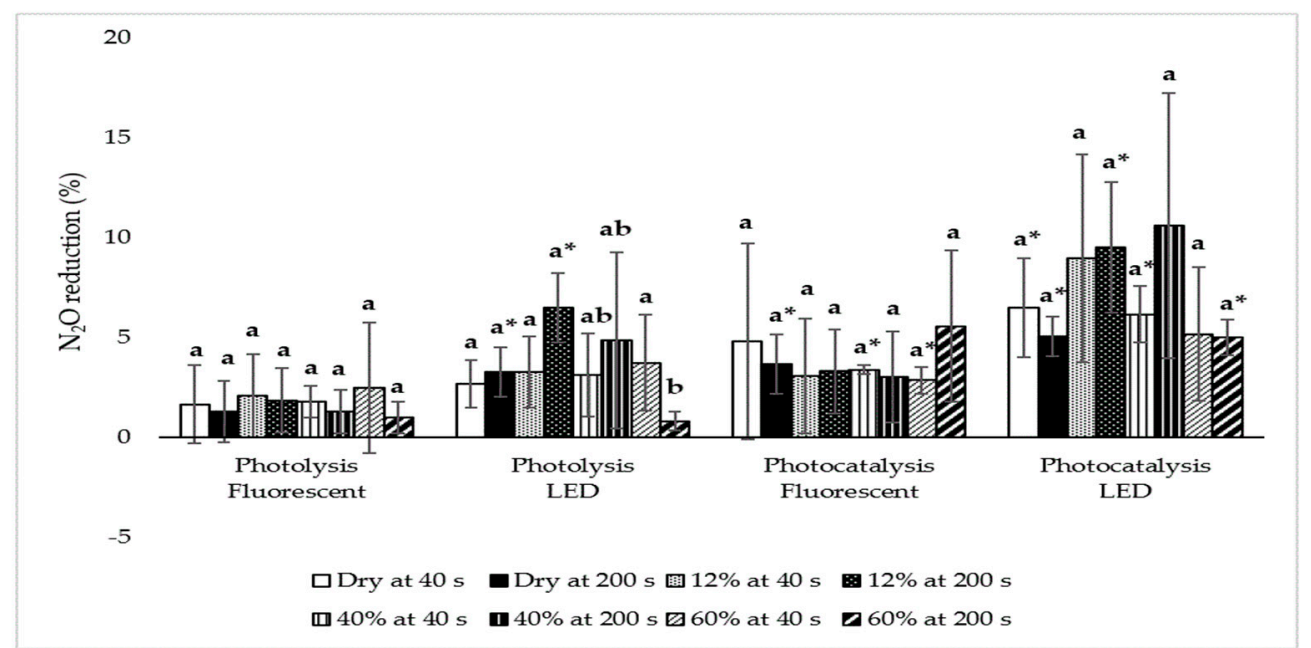

Figure 13. Comparison of $\mathrm{N}_{2} \mathrm{O}$ mitigation under different relative humidity and treatment time. Superscript $(*)$ signifies a statistical difference compared to the control $(p<0.05)$, and the different characters $(a, b)$ signify the statistical difference between treatments associated with one UV lamp type $(p<0.05)$. Error bars signify \pm standard deviation. 


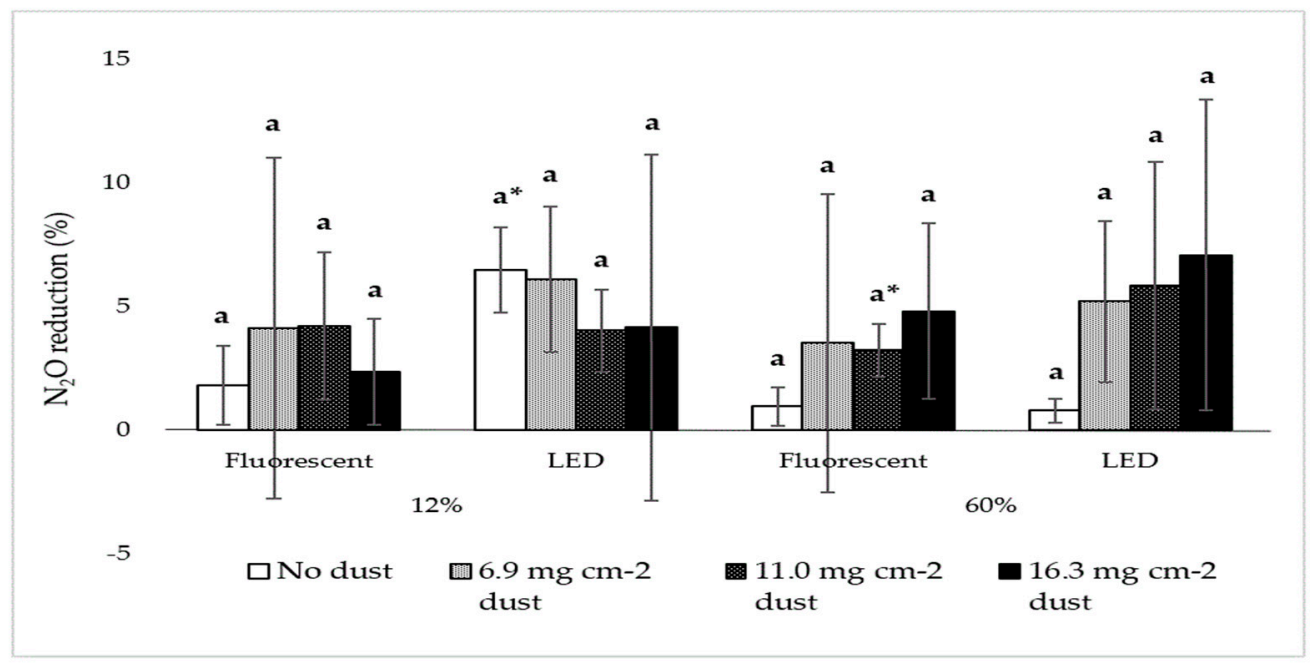

(a)

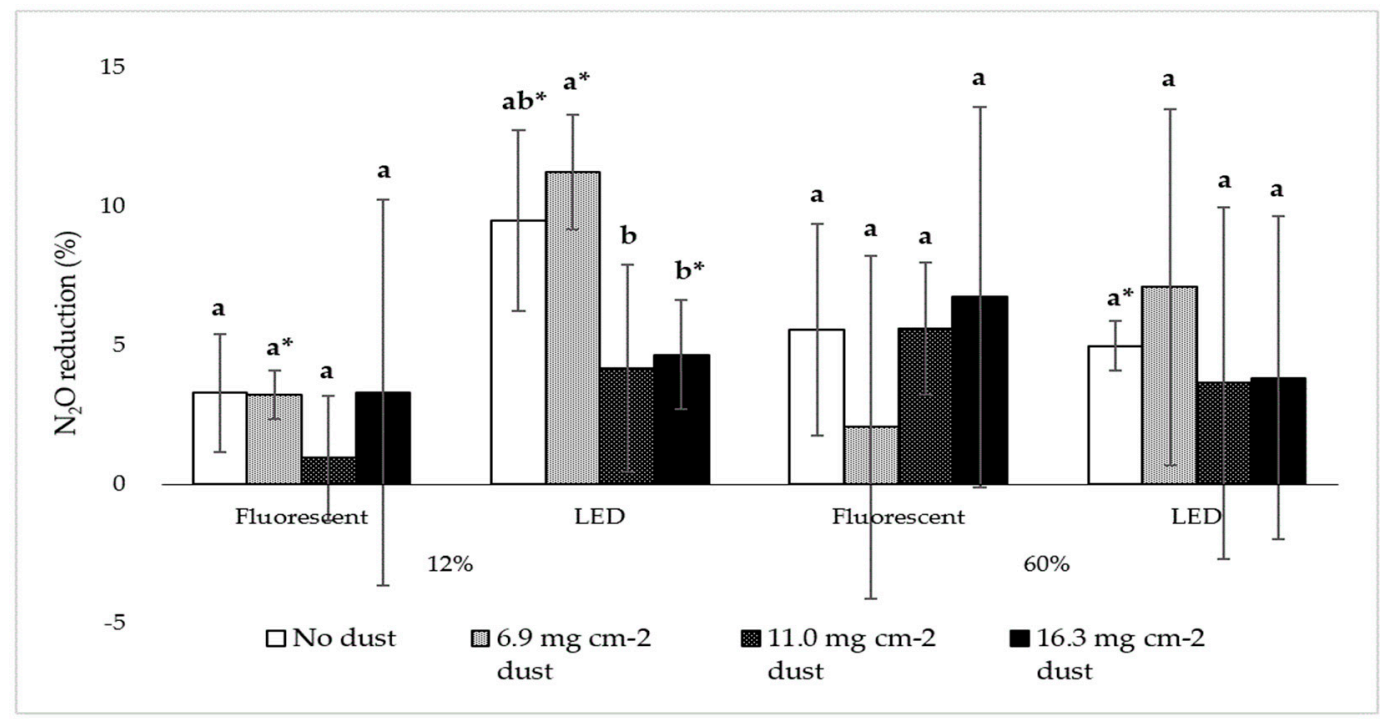

(b)

Figure 14. Comparison of $\mathrm{N}_{2} \mathrm{O}$ mitigation under different poultry dust levels at $200 \mathrm{~s}$ of treatment time. (a) \% reduction at a relative humidity of $12 \%$ and $60 \%$ in direct photolysis; (b) \% reduction at a relative humidity of $12 \%$ and $60 \%$ in photocatalysis. Superscript ${ }^{*}$ ) signifies a statistical difference compared to the control $(p<0.05)$, and the different characters $(a, b)$ signify the statistical difference between treatments associated with one UV lamp type and one relative humidity $(p<0.05)$. Error bars signify \pm standard deviation.

\subsection{Ozone}

Concerns about $\mathrm{O}_{3}$ generation when UV light is used were addressed in this research. In general, $\mathrm{O}_{3}$ concentrations were significantly reduced under direct photolysis and photocatalysis. The direct photolysis treatment did not result in a clear relationship between the controlled parameters and the $\mathrm{O}_{3} \%$ reduction. Photocatalysis resulted in an improved mitigation dependent on the light type (intensity) at $\mathrm{RH}$ of $12 \%$ and $60 \%$. However, there was no effect associated with treatment time and dust accumulation. 


\subsubsection{Comparison of Mitigation under $\mathrm{NH}_{3}$ and $\mathrm{H}_{2} \mathrm{~S}$ Standard Gas}

The average concentration of $\mathrm{O}_{3}$ in the control group was $22.6 \pm 6.5 \mathrm{ppb}$. As much as $46.5 \%$ \& $50.3 \%$ of the statistically-significant $\%$ reduction in $\mathrm{O}_{3}$ concentrations were observed for $200 \mathrm{~s}$ photocatalysis with LED at $12 \% \mathrm{RH}$ when $\mathrm{NH}_{3}$ and $\mathrm{H}_{2} \mathrm{~S}$ were treated, respectively (Table 4). However, there was no significant difference between the reduction resulting from the use of two standard gas treatments (i.e., $p$-values, Table 4). In addition, astatistically significant $\%$ reduction was found at more experimental conditions under $200 \mathrm{~s}$ treatment time compared with $40 \mathrm{~s}$.

Table 4. The mitigation of $\mathrm{O}_{3}$ at photocatalysis under $\mathrm{NH}_{3}$ and $\mathrm{H}_{2} \mathrm{~S}$ standard gas.

\begin{tabular}{|c|c|c|c|c|c|c|c|}
\hline \multirow{3}{*}{$\begin{array}{l}\text { Relative } \\
\text { Humidity }\end{array}$} & \multirow{3}{*}{$\begin{array}{l}\text { Type of } \\
\text { UV Lamp }\end{array}$} & \multicolumn{3}{|c|}{40 s Treatment Time } & \multicolumn{3}{|c|}{200 s Treatment Time } \\
\hline & & \multicolumn{2}{|c|}{ Standard Gas } & \multirow{2}{*}{$p$-Value ${ }^{1}$} & \multicolumn{2}{|c|}{ Standard Gas } & \multirow{2}{*}{$p$-Value ${ }^{1}$} \\
\hline & & $\mathrm{NH}_{3}$ & $\mathrm{H}_{2} \mathrm{~S}$ & & $\mathrm{NH}_{3}$ & $\mathrm{H}_{2} \mathrm{~S}$ & \\
\hline \multirow{2}{*}{ Dry } & Fluorescent & $33.5 \pm 15.4$ & $11.0 \pm 6.8$ & 0.22 & $27.1 \pm 2.1 *$ & $18.0 \pm 0.2 *$ & 0.13 \\
\hline & LED & $28.4 \pm 3.3^{*}$ & $31.0 \pm 1.6 *$ & 0.50 & $31.7 \pm 2.3 *$ & $25.7 \pm 0.5 *$ & 0.16 \\
\hline \multirow{2}{*}{$12 \%$} & Fluorescent & $22.0 \pm 17.6$ & $20.3 \pm 15.1$ & 0.38 & $24.4 \pm 0.9 *$ & $23.0 \pm 4.2$ & 0.27 \\
\hline & LED & $39.3 \pm 10.4$ & $34.7 \pm 3.5^{*}$ & 0.37 & $50.3 \pm 2.4 *$ & $46.5 \pm 8.0 *$ & 0.89 \\
\hline \multirow{2}{*}{$40 \%$} & Fluorescent & $34.6 \pm 24.0$ & $20.2 \pm 9.7$ & 0.67 & $22.3 \pm 0.5 *$ & $21.2 \pm 9.0 *$ & 0.57 \\
\hline & LED & $40.6 \pm 4.4^{*}$ & $31.4 \pm 6.7$ & 0.48 & $29.7 \pm 5.2 *$ & $22.4 \pm 0.7^{*}$ & 0.46 \\
\hline \multirow{2}{*}{$60 \%$} & Fluorescent & $23.2 \pm 2.5^{*}$ & $20.0 \pm 0.5^{*}$ & 0.69 & $23.4 \pm 1.2 *$ & $23.8 \pm 0.0 *$ & 0.40 \\
\hline & LED & $26.1 \pm 21.2$ & $29.1 \pm 17.5$ & 0.50 & $41.8 \pm 0.6^{*}$ & $33.3 \pm 2.5 *$ & 0.06 \\
\hline
\end{tabular}

Values in the table report the mean \pm standard deviation. Superscript $\left({ }^{1}\right)$ signifies value from the statistical analysis of the $\mathrm{N}_{2} \mathrm{O}$ concentrations reduced under the two standard gases. Superscript $\left(^{*}\right)$ means there is a statistical difference compared to the control $(p<0.05)$.

\subsubsection{Effect of Photocatalyst, Light Type, Relative Humidity, Dust, and Treatment Time on $\mathrm{O}_{3}$}

$\mathrm{O}_{3} \%$ reduction for various parameters was evaluated using the average of \% reductions for treatments of $\mathrm{NH}_{3}$ and $\mathrm{H}_{2} \mathrm{~S}$ standard gases. The was significant mitigation on direct photolysis and photocatalysis of $12.4-23.5 \%$ and $21.6-48.4 \%$, respectively (Figure 15, Tables A11 and A12). In general, photocatalysis was more effective for reducing $\mathrm{O}_{3}$ concentrations than was direct photolysis. However, there was no statistical difference between the direct photolysis and photocatalysis except the condition of $200 \mathrm{~s}$ at dry and 12\% RH (Figure 15, part b). Notably, the \% reduction increased $\sim 4 \times$ for $200 \mathrm{~s}$ photocatalysis with LED at $12 \%$ RH (Table A12).

In the case of direct photolysis, there was no clear trend and statistical significance for the treatment time, dust accumulation, lamp type, and RH (Figures 15-17, Tables A11-A14). More statistically-significant $\%$ reductions were found for $200 \mathrm{~s}$ treatments than $40 \mathrm{~s}$. Moreover, even the maximum accumulation of dust did not have a significant impact on \% reduction (Figure 17, Tables A15 and A16). 


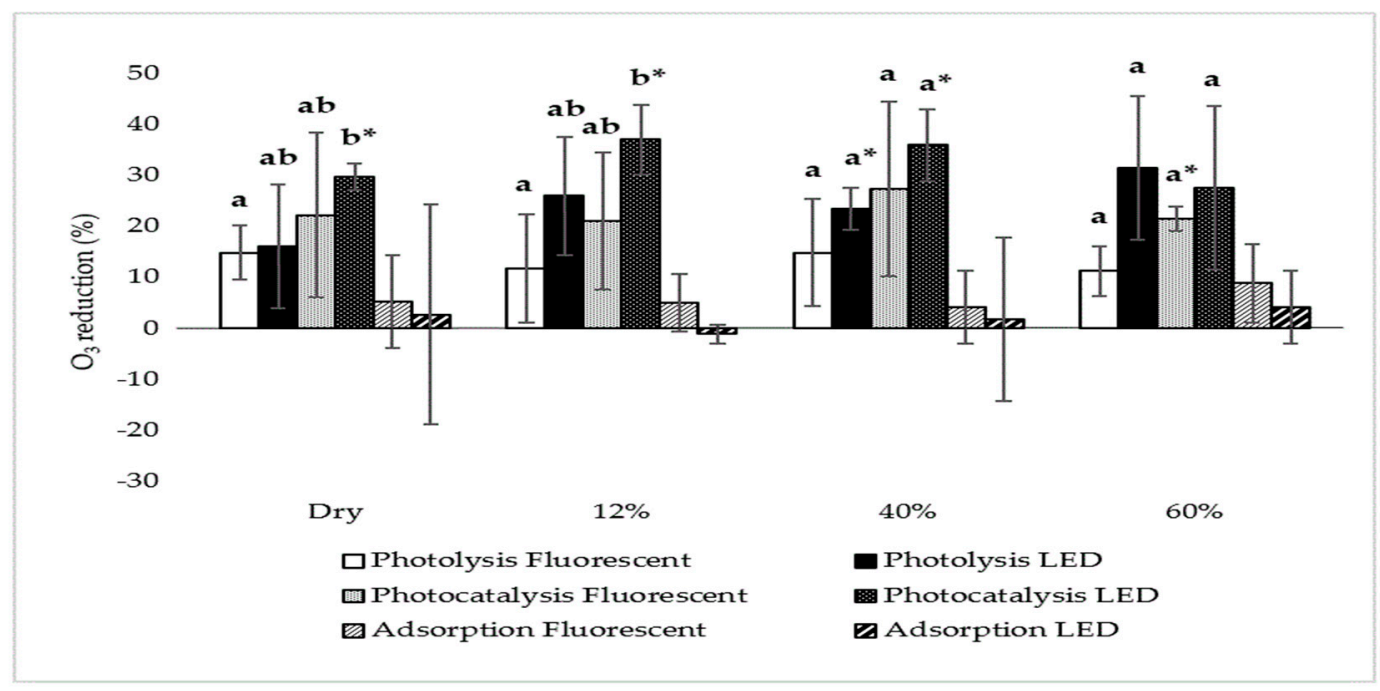

(a)

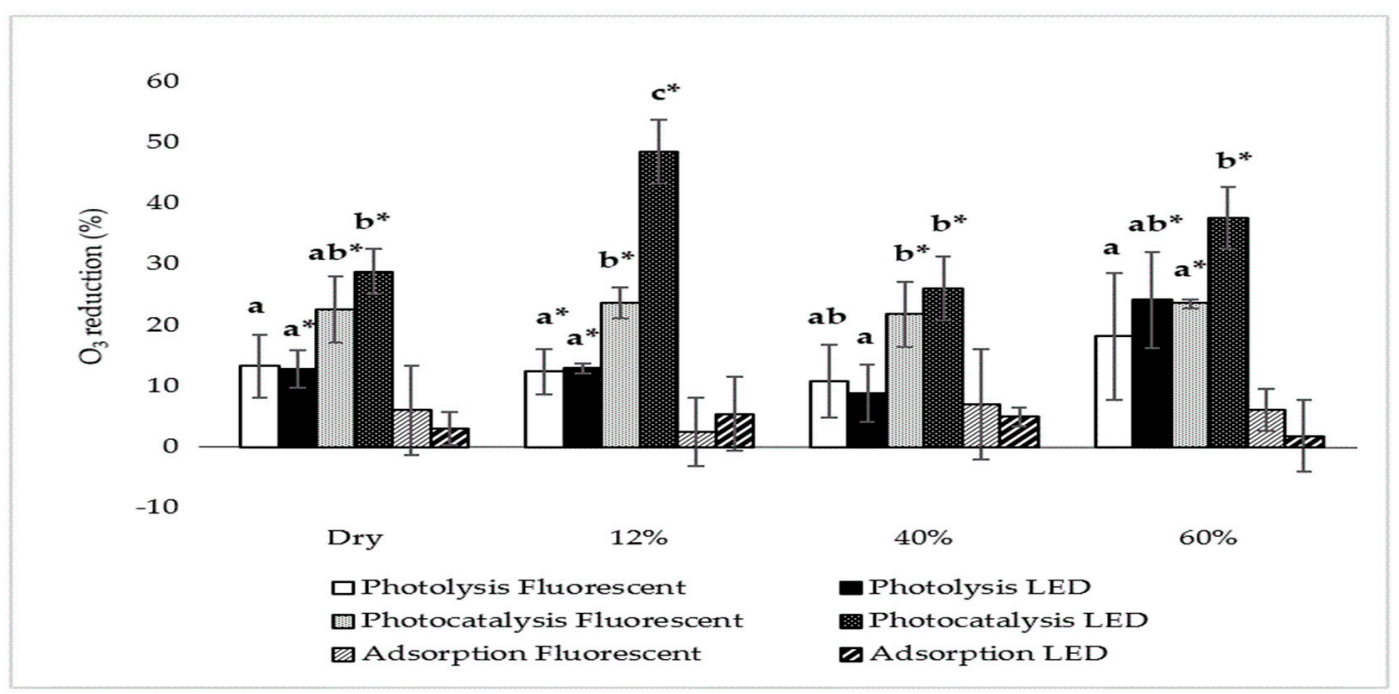

(b)

Figure 15. Comparison of $\mathrm{O}_{3}$ mitigation under different treatment types and light intensity. (a) \% reduction at treatment time of $40 \mathrm{~s}$; (b) \% reduction at treatment time of $200 \mathrm{~s}$; Superscript ${ }^{*}$ ) signifies a statistical difference compared to the control $(p<0.05)$, and the different characters $(a, b)$ signify a statistical difference when comparing different light intensities (fluorescent vs. LED) at the same relative humidity $(p<0.05)$. Error bars signify \pm standard deviation. 


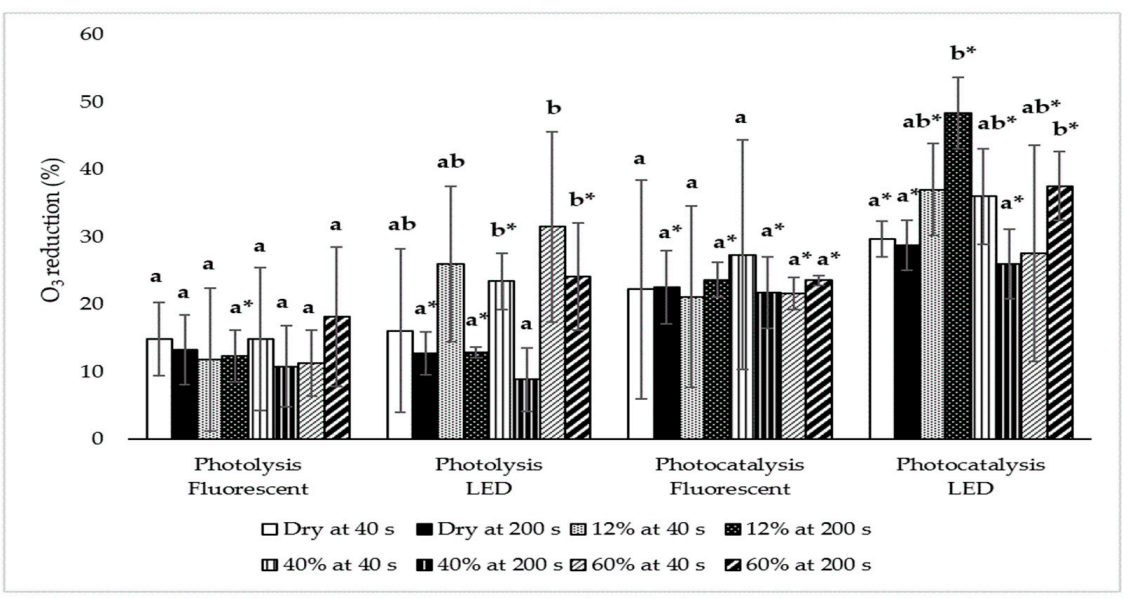

Figure 16. Comparison of $\mathrm{O}_{3}$ mitigation under different relative humidity and treatment time. Superscript $(*)$ signifies a statistical difference compared to the control $(p<0.05)$, and the different characters $(a, b)$ signify a statistical difference between treatments associated with a lamp type $(p<0.05)$. Error bars signify \pm standard deviation.

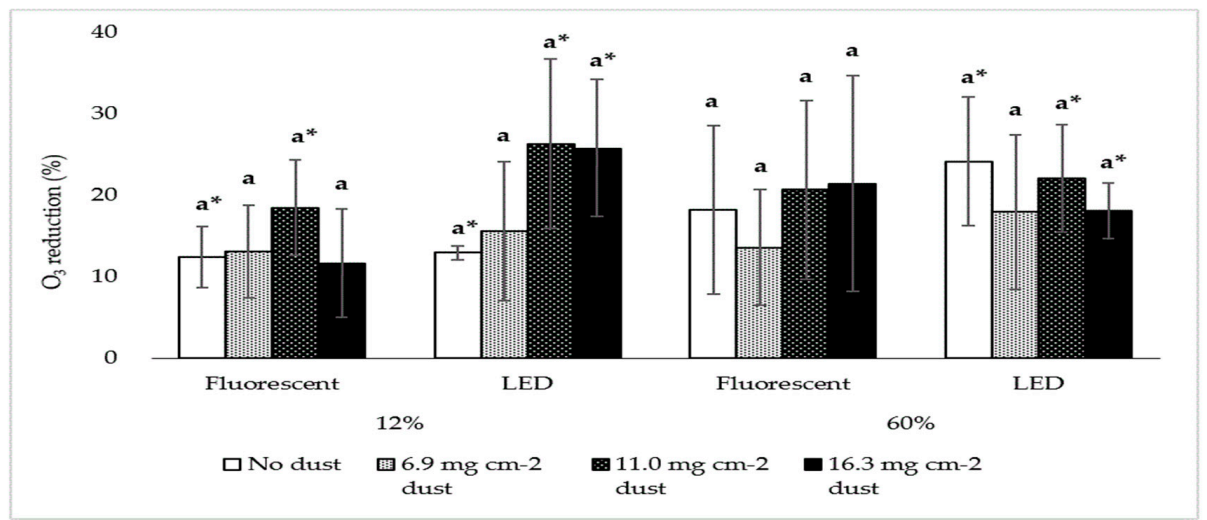

(a)

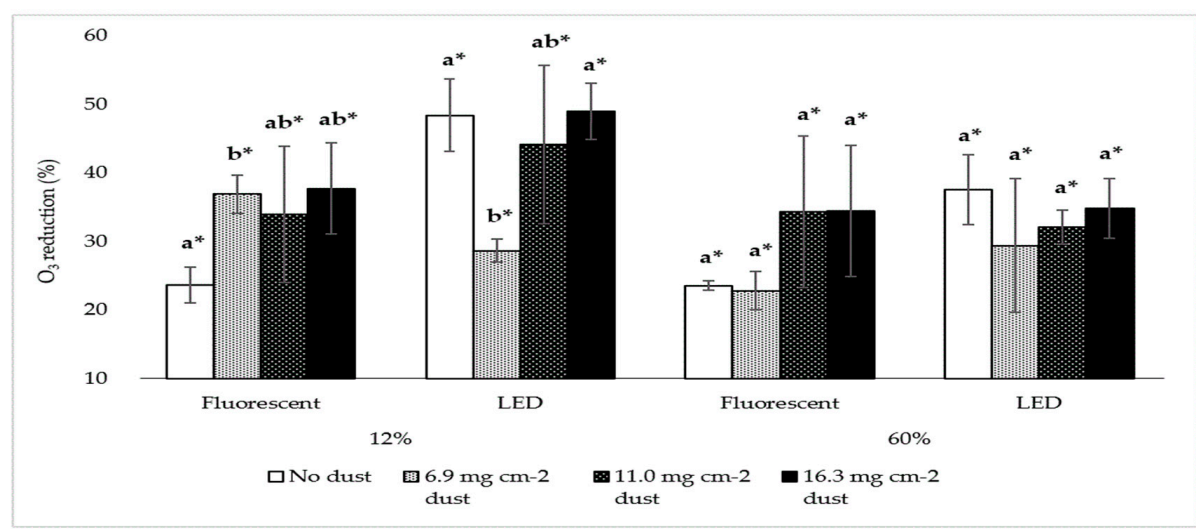

(b)

Figure 17. Comparison of $\mathrm{O}_{3}$ mitigation under different poultry dust levels. (a) \% reduction at a relative humidity of $12 \%$ and $60 \%$ in direct photolysis; (b) $\%$ reduction at a relative humidity of $12 \%$ and $60 \%$ in photocatalysis. Superscript $\left.{ }^{*}\right)$ signifies a statistical difference compared to the control $(p<0.05)$, and the different characters $(a, b)$ signify the statistical difference between treatments associated with one UV lamp type and one relative humidity $(p<0.05)$. Error bars signify \pm standard deviation. 


\section{Discussion}

\subsection{Ammonia and Hydrogen Sulfide}

In this study, $\mathrm{NH}_{3}$ mitigation was only effective when photocatalysis was used, regardless of the type of UV lamp, which is generally consistent with previous research. Research [37,38] suggests that a shorter wavelength (e.g., $220 \mathrm{~nm}$ ) is needed to mitigate $\mathrm{NH}_{3}$ with photolysis. Other researchers have also reported on the weak adsorption of $\mathrm{NH}_{3}$ to the $\mathrm{TiO}_{2}$ coated surface at room temperature $[39,40]$.

The greatest mitigation of $\mathrm{NH}_{3}$ was at $12 \% \mathrm{RH}$ in photocatalysis. The \% reduction decreased with either dry air or increasing RH. In general, the higher \% reduction is achieved under low (or dry) humidity conditions. This is due to the adsorption of water on the $\mathrm{TiO}_{2}$ surface $[39,41,42]$, which, in turn, inhibits the mitigation of the target substances [43-45]. A similar trend (at least for low RH) was observed in this study. However, the \% reduction was found to be decreased in the dry condition, which was expected to show the highest \% reduction. One explanation could be that the decreased \% reduction in dry conditions is due to the absence of $\mathrm{HO}$ radicals produced by the photocatalysis of water. $\mathrm{HO}$ radicals make it easier to oxidize $\mathrm{NH}_{3}$ [46]. The optimal $\mathrm{RH}$ for the \% reduction is different depending on the type of target gas. The comparison of optimum RH for selected target gases in the photocatalysis is summarized in Table 5.

Table 5. Comparison of optimum relative humidity for each target gases in the photocatalysis.

\begin{tabular}{|c|c|c|c|c|}
\hline Reference & Target Gas & $\begin{array}{c}\text { UV Type } \\
\text { (Wavelength) }\end{array}$ & $\begin{array}{l}\text { Coating Material } \\
\text { (Dose) }\end{array}$ & $\begin{array}{c}\text { The Relative Humidity } \\
\text { Condition for Optimal \% } \\
\text { Reduction }\end{array}$ \\
\hline [42] & Ammonia & $\begin{array}{c}\text { UV-A } \\
(355 \mathrm{~nm})\end{array}$ & $\begin{array}{c}\mathrm{TiO}_{2}-\mathrm{P} 25 \\
\left(650 \mu \mathrm{g} \cdot \mathrm{cm}^{-2}\right)\end{array}$ & Low $>$ High \\
\hline [43] & Toluene & $\begin{array}{c}\text { UV-A } \\
(315-400 \mathrm{~nm})\end{array}$ & $\begin{array}{c}\mathrm{TiO}_{2}-\mathrm{P} 25 \\
\text { (Not reported) }\end{array}$ & Dry $(1 \%)$ \\
\hline [44] & Acetaldehyde & $\begin{array}{c}\text { UV-A } \\
(365 \mathrm{~nm})\end{array}$ & $\begin{array}{c}\mathrm{TiO}_{2} \\
\text { (Not reported) }\end{array}$ & Dry \\
\hline [47] & Trichloroethylene & $\begin{array}{c}\text { UV-A } \\
\text { (Not reported) }\end{array}$ & $\begin{array}{l}\mathrm{TiO}_{2} \text { sol-gel films } \\
\left(\sim 1 \mathrm{mg} \cdot \mathrm{cm}^{-2}\right)\end{array}$ & $<50 \%$ \\
\hline [48] & Trichloroethylene & $\begin{array}{c}\text { UV-A } \\
\text { (Not reported) }\end{array}$ & $\begin{array}{l}\mathrm{TiO}_{2}-\mathrm{GFC} \\
\left(4.8 \mathrm{~g} \cdot \mathrm{cm}^{-2}\right)\end{array}$ & $<25 \%$ \\
\hline [49] & $\begin{array}{c}\text { Hydrogen sulfide } \\
\text { Volatile organic } \\
\text { compounds }\end{array}$ & $\begin{array}{c}\text { UV-A } \\
\text { (Not reported) }\end{array}$ & $\begin{array}{l}\mathrm{TiO}_{2} \text {-ceramic filter } \\
\text { (Not reported) }\end{array}$ & No impact (40-80\%) \\
\hline [50] & $\begin{array}{l}\text { Hydrocarbons } \\
\text { mixture }\end{array}$ & $\begin{array}{l}\text { Not reported } \\
(280-650 \mathrm{~nm})\end{array}$ & $\begin{array}{c}\mathrm{TiO}_{2}-\mathrm{P} 25 \\
\text { (Thickness of } 1-2 \mathrm{~mm} \text { ) }\end{array}$ & Dry \\
\hline This study & Ammonia & $\begin{array}{c}\text { UV-A } \\
(365 \mathrm{~nm})\end{array}$ & $\begin{array}{c}\mathrm{TiO}_{2} \\
\left(10 \mu \mathrm{g} \cdot \mathrm{cm}^{-2}\right)\end{array}$ & $12 \%$ \\
\hline
\end{tabular}

Table 6 summarize previous research on the \% reduction of selected target gases important in animal production systems via photocatalysis with UV-A. The \% reduction of $\mathrm{NH}_{3}$ was $\sim 30 \%$, but it required longer treatment $(>6 \mathrm{~min})$. In this study, the $\%$ reduction was $\sim 9 \%$ on average (max: $18.7 \%$, min: $2.56 \%$ ) and $200 \mathrm{~s}$. In general, the \% reduction increases as the UV light intensity and treatment time of photocatalysis action increase [38,47,51]. This study also showed an increase in $\mathrm{NH}_{3}$ $\%$ reduction with increasing light intensity and treatment time. 
Table 6. Summary of mitigation for selected target gas in photocatalysis with UV-A.

\begin{tabular}{|c|c|c|c|c|c|}
\hline Reference & $\begin{array}{l}\text { Experiment } \\
\text { Conditions }\end{array}$ & $\begin{array}{l}\text { Coating } \\
\text { Material }\end{array}$ & $\begin{array}{c}\text { UV Type } \\
\text { (Wavelength) }\end{array}$ & Light Intensity & $\begin{array}{l}\text { Target Gas } \\
\text { (\% Ave } 1 \\
\text { Reduction) }\end{array}$ \\
\hline [1] & $\begin{array}{c}\text { Swine farm } \\
\text { Temp }^{2}: 21.8-26.0^{\circ} \mathrm{C} \\
\text { RH }^{3}: 36-80 \% \\
\text { T time }^{4}(\mathrm{~s}): 24,47\end{array}$ & $\begin{array}{c}\mathrm{TiO}_{2} \\
\left(10 \mu \mathrm{g} \cdot \mathrm{cm}^{2}\right)\end{array}$ & $\begin{array}{c}\text { UV-A } \\
(365 \mathrm{~nm})\end{array}$ & $\begin{array}{c}<0.04 \\
\mathrm{~mW} \cdot \mathrm{cm}^{-2}\end{array}$ & $\begin{array}{c}\mathrm{CH}_{4}(-2.2) \\
\mathrm{CO}_{2}(-3.1) \\
\mathrm{N}_{2} \mathrm{O}(8.7) \\
\text { Odor }(16.3) \\
\text {-cresol (22.0) }\end{array}$ \\
\hline [18] & $\begin{array}{c}\text { Swine farm } \\
\text { Temp: } 25.7^{\circ} \mathrm{C} \\
\text { RH: } 56.0 \% \\
\text { CMM: } 271.1 \\
\text { T time (s): } 71.6\end{array}$ & $\begin{array}{c}\mathrm{TiO}_{2} \\
\left(7 \mathrm{mg} \cdot \mathrm{cm}^{-2}\right)\end{array}$ & $\begin{array}{c}\text { UV-A } \\
(315-400 \mathrm{~nm})\end{array}$ & Not reported & $\begin{array}{l}\mathrm{NH}_{3}(2.0) \\
\mathrm{CH}_{4}(27.4) \\
\mathrm{CO}_{2}(-4.5) \\
\mathrm{N}_{2} \mathrm{O}(-0.8) \\
\mathrm{PM}_{10}(17.0) \\
\mathrm{PM}_{2.5}(-8.1)\end{array}$ \\
\hline [19] & $\begin{array}{c}\text { Swine farm } \\
\text { Temp: } 24.3^{\circ} \mathrm{C} \\
\text { RH: } 53.6 \% \\
\text { CMM: } 74.9 \\
\text { T time (s): } 364.2\end{array}$ & $\begin{array}{c}\mathrm{TiO}_{2} \\
\left(7 \mathrm{mg} \cdot \mathrm{cm}^{-2}\right)\end{array}$ & $\begin{array}{c}\text { UV-A } \\
(315-400 \mathrm{~nm})\end{array}$ & Not reported & $\begin{array}{l}\mathrm{NH}_{3}(30.5) \\
\mathrm{CH}_{4}(10.8) \\
\mathrm{CO}_{2}(15.3) \\
\mathrm{N}_{2} \mathrm{O}(4.2)\end{array}$ \\
\hline [52] & $\begin{array}{c}\text { Lab-scale } \\
\text { Temp: } 24^{\circ} \mathrm{C} \\
\text { RH: } 50 \% \\
\text { T time (min): }>30\end{array}$ & $\begin{array}{c}\mathrm{TiO}_{2} \\
\text { (Not reported) }\end{array}$ & $\begin{array}{c}\text { UV-A } \\
(365 \mathrm{~nm})\end{array}$ & $0.46 \mathrm{~mW} \cdot \mathrm{cm}^{-2}$ & $\mathrm{NH}_{3}(35.0)$ \\
\hline This study & $\begin{array}{c}\text { Lab-scale } \\
\text { Temp: } 25 \pm 3{ }^{\circ} \mathrm{C} \\
\text { RH: Dry, } 12 \%, 40 \%, 60 \% \\
\text { T time (s): } 40,200\end{array}$ & $\begin{array}{c}\mathrm{TiO}_{2} \\
\left(10 \mu \mathrm{g} \cdot \mathrm{cm}^{-2}\right)\end{array}$ & $\begin{array}{c}\text { UV-A } \\
(365 \mathrm{~nm})\end{array}$ & $\begin{array}{l}0.44 \mathrm{vs} .4 .85 \\
\mathrm{~mW} \cdot \mathrm{cm}^{-2}\end{array}$ & $\begin{array}{c}\mathrm{NH}_{3}(4.8 \text { vs. } 9.3) \\
\mathrm{H}_{2} \mathrm{~S}(-2.1 \text { vs. } 1.7) \\
\mathrm{CH}_{4}(3.4 \text { vs. } 2.1) \\
\mathrm{CO}_{2}(-3.1 \text { vs. } 3.8) \\
\mathrm{N}_{2} \mathrm{O}(3.3 \text { vs. } 6.6) \\
\mathrm{O}_{3}(22.6 \text { vs. } 34.7)\end{array}$ \\
\hline
\end{tabular}

Note: ${ }^{1}$ Mean; ${ }^{2}$ Temperature; ${ }^{3}$ Relative humidity; ${ }^{4}$ Treatment time; Bold font signifies a statistical diff. $(p<0.05)$.

Photocatalysis was affected by dust accumulation. In particular, the increase in dust at high $\mathrm{RH}$ conditions canceled the $\mathrm{NH}_{3} \%$ reduction effect. This is because when dust accumulated, poultry dust continually increased the absorption of the UV light. Zhu et al. [21] reported that dust accumulation (in a swine barn) had no effect on the \% reduction of VOCs. In this study, $\mathrm{H}_{2} \mathrm{~S}$ showed no \% reduction effect in the treatment system using UV-A light and $\mathrm{TiO}_{2}$ based photocatalysis. Previous studies with higher $\mathrm{TiO}_{2}$ coating density and light intensity have shown a mitigation effect $[53,54]$.

\subsection{Greenhouse Gases and Ozone}

$\mathrm{CH}_{4}$ was not affected by any treatment in this study. The results add to a mixed body of knowledge. Our previous study with PureTi coating [1] did not show a statistically significant \% reduction. Another research reported photocatalytic $\mathrm{CH}_{4} \%$ reduction at a low product yield and low energy efficiency [55]. However, two previous studies [18,19] (UV-A light) reported an 11-27\% reduction. The reasons for our lack of apparent treatment could be due to low $\mathrm{TiO}_{2}$ coating density, and the possibility that the mitigation effect was offset by forming $\mathrm{CH}_{4}$ from the reduction of $\mathrm{CO}_{2}$ [56-58].

$\mathrm{CO}_{2}$ showed a $3.8 \%$ mitigation only under the RH of $12 \%$ with $200 \mathrm{~s}$ of LED irradiation. Although there is previous research demonstrating photocatalytic reduction of $\mathrm{CO}_{2}$ to $\mathrm{CH}_{4}$ under specific conditions [59], there is no chemical reason to expect that photocatalysis under these conditions (aerobic atmosphere and standard $\mathrm{TiO}_{2}$ catalyst) could reduce $\mathrm{CO}_{2}$; in fact, $\mathrm{CO}_{2}$ is the oxidative endpoint for photocatalytic oxidation of virtually all carbon-containing compounds. It is thus tempting to suggest that an indirect mechanism for any observed $\mathrm{CO}_{2}$ mitigation must exist, such as conversion to carbonates or surface absorption. By whatever mechanism, similar $\mathrm{CO}_{2}$ concentration reductions were also observed by previous studies $[19,58]$. 
$\mathrm{N}_{2} \mathrm{O}$ and $\mathrm{O}_{3}$ were mitigated in both direct photolysis and photocatalysis. In general, $\mathrm{N}_{2} \mathrm{O}$ and $\mathrm{O}_{3}$ are known not to absorb significantly in the UV-A range, meaning that they are not subject to direct photolytic degradation at these wavelengths. However, indirect effects through more complex reaction paths can certainly affect their observed concentrations. Similarly, under photocatalytic conditions, where direct absorption by the substrate is not required, reasonably direct removal can occur. Previous research [60] reported that the $\mathrm{N}_{2} \mathrm{O}$ photolysis rate was inhibited at $>230 \mathrm{~nm}$, and [61] reported that $\mathrm{O}_{3}$ $\%$ reduction does not occur efficiently at $>305 \mathrm{~nm}$. However, this and our previous study [1] showed the mitigation effect of $\mathrm{N}_{2} \mathrm{O}$ and $\mathrm{O}_{3}$ under $365 \mathrm{~nm}$. In the case of $\mathrm{N}_{2} \mathrm{O}$, the \% reduction was about $3.3-6.5 \%$, also in the case of $\mathrm{O}_{3}$, the \% reduction was $12.4-24.1 \%$ (Table 7 ).

Table 7. Comparison of mitigation of the $\mathrm{N}_{2} \mathrm{O}$ and $\mathrm{O}_{3}$ in photolysis and photocatalysis.

\begin{tabular}{cccc}
\hline \multirow{2}{*}{ Reference } & \multirow{2}{*}{ Treatment Time } & Direct Photolysis & Photocatalysis \\
\cline { 3 - 4 } & & \multicolumn{2}{c}{ Target Gas (\% Reduction) } \\
\cline { 3 - 4 }$[1]$ & $24 \mathrm{~s}$ & $\mathrm{~N}_{2} \mathrm{O}(4.2)$ & $\mathrm{N}_{2} \mathrm{O}(7.3)$ \\
& $47 \mathrm{~s}$ & $\mathrm{~N}_{2} \mathrm{O}(7.6)$ & $\mathrm{N}_{2} \mathrm{O}(8.7)$ \\
\hline \multirow{3}{*}{ This study } & \multirow{3}{*}{$40 \mathrm{~s}$} & $\mathrm{~N}_{2} \mathrm{O}(\mathrm{No} \%$ & $\mathrm{N}_{2} \mathrm{O}(2.8-6.8)$ \\
& \multirow{2}{*}{$200 \mathrm{~s}$} & reduction) & $\mathrm{O}_{3}(21.6-37.0)$ \\
& & $\mathrm{O}_{3}(23.5)$ & $\mathrm{N}_{2} \mathrm{O}(3.7-9.5)$ \\
& & $\mathrm{N}_{2} \mathrm{O}(3.3-6.5)$ & $\mathrm{O}_{3}(21.8-48.4)$ \\
\hline
\end{tabular}

As expected, photocatalysis showed higher mitigation for $\mathrm{N}_{2} \mathrm{O}$ than direct photolysis. However, this study result is quite different from those of previous studies. This is because previous research $[20,37,38,51,52,62]$ indicates that by-products like $\mathrm{N}_{2} \mathrm{O}$ and $\mathrm{N}_{2}$ are generated via photocatalysis reaction in the presence of $\mathrm{NH}_{3}$, butthe levels of $\mathrm{N}_{2} \mathrm{O}$ and $\mathrm{N}_{2}$ vary according to treatment conditions and wavelength. Only one previous study showed a consistent trend with this study [1]. In theory, $\mathrm{TiO}_{2}$ could only be activated by UV light with a wavelength of $<387.5 \mathrm{~nm}$ due to its considerable bandgap energy $[63,64]$. Also, $\mathrm{N}_{2} \mathrm{O}$ has been reported to be mitigated with UV-A, although its efficiency is lower than that of UV-C [63]. How much of this process actually decrease the $\mathrm{N}_{2} \mathrm{O}$ produced by $\mathrm{NH}_{3}$ decomposition has not been investigated in this study. However, the low but statistically significant $\%$ reduction could be due to other factors such as direct reduction by photocatalysis, indirect reduction by electrochemical reactions during the decomposition of other substances such as $\mathrm{O}_{3}$, and adsorption of by-products on the $\mathrm{TiO}_{2}$.

In the case of $\mathrm{O}_{3}$, the previous results are different depending on the type of $\mathrm{TiO}_{2}$ coating material, but it is reported that $\mathrm{O}_{3}$ reduction does not occur $>290 \mathrm{~nm}$ with $\mathrm{TiO}_{2}$ [65]. However, $\mathrm{O}_{3}$ has been reported to increase the reduction of target gas through the formation of ozonide radicals during photocatalysis [66-69]. Thus, during photocatalysis, $\mathrm{O}_{3}$ concentration can be reduced due to the formation of ozonide radicals that are beneficial for reducing other target gases. In this study, the \% reduction was 3.4-9.7\% for $\mathrm{N}_{2} \mathrm{O}$ and $20.4-48.4 \%$ for $\mathrm{O}_{3}$.

\section{Conclusions}

The results of the study provide evidence that photocatalysis with $\mathrm{TiO}_{2}$ coating and UV-A light can reduce gas concentrations of $\mathrm{NH}_{3}, \mathrm{CO}_{2}, \mathrm{~N}_{2} \mathrm{O}$, and $\mathrm{O}_{3}$; without significant effect on $\mathrm{H}_{2} \mathrm{~S}$ and $\mathrm{CH}_{4}$. The particular \% reduction depends on the presence of photocatalyst, $\mathrm{RH}$, light type (intensity), treatment time, and dust accumulation on the photocatalyst surface. In the case of $\mathrm{NH}_{3}$, the \% reduction varied from $2.6-18.7 \%$ and was affected by $\mathrm{RH}$ and light intensity. The \% reduction of $\mathrm{NH}_{3}$ was the highest at $12 \% \mathrm{RH}$ and increased with treatment time and light intensity. The \% reduction of $\mathrm{NH}_{3}$ decreased with the accumulation of poultry dust. The \% reduction for $\mathrm{H}_{2} \mathrm{~S}$ had no statistical difference under any experimental conditions. The proposed treatment of $\mathrm{NH}_{3}$ and $\mathrm{H}_{2} \mathrm{~S}$ was evaluated for a potential impact on important ambient air quality parameters, the possibility of simultaneously 
mitigating/generating GHGs. There was no statistically significant change in $\mathrm{CH}_{4}$ concentrations under any tested conditions. $\mathrm{CO}_{2}$ was reduced at 3.8-4.4\%. $\mathrm{N}_{2} \mathrm{O}$ and $\mathrm{O}_{3}$ concentrations were reduced by both direct photolysis and photocatalysis, with the latter having greater \% reductions. As much as $6.9-12.2 \%$ of the statistically-significant \% reduction of $\mathrm{N}_{2} \mathrm{O}$ was observed. The \% reduction for $\mathrm{O}_{3}$ ranged from $12.4-48.4 \%$. The results warrant scaling up to pilot-scale where the technology could be evaluated with economic analyses. It is necessary to investigate the practical applicability to the real system through large scale studies.

Author Contributions: Conceptualization, J.A.K., W.J.; methodology, J.A.K.; validation, M.L., J.W., H.A., \& J.A.K.; formal analysis, M.L., J.W.; investigation, M.L., J.W., P.L., B.C., Z.M., \& C.B.; resources, P.L., B.C., Z.M., C.B., and J.A.K.; data curation, M.L., J.A.K.; writing—original draft preparation, M.L.; writing-review and editing, M.L., H.A., J.A.K., \& W.J.; visualization, M.L.; supervision, H.A., J.A.K.; project administration, J.A.K., W.J.; funding acquisition, J.A.K., W.J. All authors have read and agreed to the published version of the manuscript.

Funding: This research was supported by US Poultry \& Egg Association Project \#F080 "Mitigation of Ammonia and Odor Emissions: Improving Indoor Air Quality in Poultry Housing with Black UV Light." The research was made possible in part by an endowing Foundation gift from Koch Foods. This research was partially supported by the Iowa Agriculture and Home Economics Experiment Station, Ames, Iowa. Project no. IOW05556 (Future Challenges in Animal Production Systems: Seeking Solutions through Focused Facilitation) sponsored by Hatch Act \& State of Iowa funds. The authors would like to thank the Ministry of Education and Science of the Republic of Kazakhstan for supporting Zhanibek Meiirkhanuly with a Master of Science (M.S.) study scholarship via the Bolashak Program.

Acknowledgments: This authors gratefully acknowledge Woosang Lee (Smart Control \& Sensing Inc.) for his help with the gas monitoring system, Cameron Hall (ISU Poultry Teaching Farm) for facilitating the on-farm collection of poultry dust, Aaron Stephan and Hoa-Thanh Huynh from ONCE Innovations for the LED array and Bikash Rajkarnikar (PureTi) for coating with a photocatalyst.

Conflicts of Interest: The author does not declare a conflict of interest. The funders did not play any role in the study design, data collection, analysis, interpretation, and decision to write a manuscript or present results.

\section{Appendix A}

Table A1. $\mathrm{NH}_{3}$ mitigation under different light types and relative humidity at a treatment time of $40 \mathrm{~s}$. Value in the table report $\%$ reduction \pm standard deviation ( $p$-value). Bold font signifies statistical significance.

\begin{tabular}{ccccc}
\hline $\begin{array}{c}\text { Relative } \\
\text { Humidity }\end{array}$ & $\begin{array}{c}\text { Type of } \\
\text { UV lamp }\end{array}$ & $\begin{array}{c}\text { Direct Photolysis } \\
\text { (UV only) }\end{array}$ & $\begin{array}{c}\text { Photocatalysis } \\
\left(\mathbf{U V}+\mathbf{T i O}_{\mathbf{2}} \text { ) }\right.\end{array}$ & $\begin{array}{c}\text { Adsorption } \\
\text { (to } \text { TiO }_{\mathbf{2}} \text { ) }\end{array}$ \\
\hline \multirow{2}{*}{ Dry } & Fluorescent & $0.0 \pm 0.0$ & $2.6 \pm 0.8(0.03)$ & $1.2 \pm 2.0$ \\
& LED & $1.2 \pm 2.0$ & $3.8 \pm 1.3(0.04)$ & $2.7 \pm 2.7$ \\
\hline \multirow{2}{*}{$12 \%$} & Fluorescent & $-1.2 \pm 2.0$ & $7.3 \pm 0.6(0.00)$ & $2.0 \pm 1.8$ \\
& LED & $0.0 \pm 0.0$ & $10.4 \pm 3.4(0.03)$ & $4.3 \pm 2.1$ \\
\hline \multirow{2}{*}{$40 \%$} & Fluorescent & $0.0 \pm 0.0$ & $5.0 \pm 1.5(0.03)$ & $0.0 \pm 0.0$ \\
& LED & $0.0 \pm 0.0$ & $7.3 \pm 1.2(0.00)$ & $1.2 \pm 2.0$ \\
\hline \multirow{2}{*}{$60 \%$} & Fluorescent & $0.0 \pm 0.0$ & $3.1 \pm 0.4(0.01)$ & $1.1 \pm 1.9$ \\
& LED & $0.0 \pm 0.0$ & $5.1 \pm 3.1(0.08)$ & $2.1 \pm 1.8$ \\
\hline \multirow{2}{*}{ Average } & Fluorescent & $-0.3 \pm 1.0$ & $4.5 \pm 2.1$ & $1.1 \pm 1.6$ \\
& LED & $0.3 \pm 1.0$ & $6.7 \pm 3.3$ & $2.6 \pm 2.2$ \\
\hline
\end{tabular}


Table A2. $\mathrm{NH}_{3}$ mitigation under different light types and relative humidity at a treatment time of $200 \mathrm{~s}$. Values in the table report $\%$ reduction \pm standard deviation ( $p$-value). Bold font signifies statistical significance.

\begin{tabular}{ccccc}
\hline $\begin{array}{c}\text { Relative } \\
\text { Humidity }\end{array}$ & $\begin{array}{c}\text { Type of } \\
\text { UV Lamp }\end{array}$ & $\begin{array}{c}\text { Direct Photolysis } \\
\text { (UV only) }\end{array}$ & $\begin{array}{c}\text { Photocatalysis } \\
\left(\mathbf{U V}+\mathbf{T i O}_{\mathbf{2}} \text { ) }\right.\end{array}$ & $\begin{array}{c}\text { Adsorption } \\
\text { (to } \mathbf{T i O}_{\mathbf{2}} \text { ) }\end{array}$ \\
\hline \multirow{2}{*}{ Dry } & Fluorescent & $0.0 \pm 0.0$ & $3.1 \pm 0.4(0.00)$ & $2.2 \pm 1.9$ \\
& LED & $0.0 \pm 0.0$ & $5.2 \pm 1.6(0.03)$ & $3.0 \pm 2.8$ \\
\hline \multirow{2}{*}{$12 \%$} & Fluorescent & $0.0 \pm 0.0$ & $9.4 \pm 1.3(0.00)$ & $4.0 \pm 3.5$ \\
& LED & $0.0 \pm 0.0$ & $18.7 \pm 2.0(0.00)$ & $1.8 \pm 1.6$ \\
\hline \multirow{2}{*}{$40 \%$} & Fluorescent & $0.0 \pm 0.0$ & $5.3 \pm 2.4(0.05)$ & $1.1 \pm 1.9$ \\
& LED & $0.0 \pm 0.0$ & $13.5 \pm 2.6(0.01)$ & $2.0 \pm 1.8$ \\
\hline \multirow{2}{*}{$60 \%$} & Fluorescent & $0.0 \pm 0.0$ & $3.2 \pm 0.4(0.00)$ & $0.0 \pm 0.0$ \\
& LED & $1.9 \pm 3.2$ & $6.2 \pm 0.6(0.00)$ & $1.9 \pm 3.2$ \\
\hline \multirow{2}{*}{ Average } & Fluorescent & $0.0 \pm 0.0$ & $5.3 \pm 2.9$ & $1.8 \pm 2.4$ \\
& LED & $0.5 \pm 1.6$ & $10.9 \pm 6.0$ & $2.2 \pm 2.1$ \\
\hline
\end{tabular}

Table A3. $\mathrm{NH}_{3}$ mitigation under the different dust levels at a relative humidity of dry and $12 \%$. Values in the table report $\%$ reduction \pm standard deviation ( $p$-value). Bold font signifies statistical significance.

\begin{tabular}{cccccc}
\hline \multicolumn{2}{c}{ Relative Humidity } & \multicolumn{2}{c}{ Dry } & \multicolumn{2}{c}{$\mathbf{1 2 \%}$} \\
\hline \multicolumn{2}{c}{ Treatment Time } & $\mathbf{4 0 ~ s}$ & $\mathbf{2 0 0} \mathbf{~ s}$ & $\mathbf{4 0 ~ s}$ & $\mathbf{2 0 0 ~ s}$ \\
\hline \multirow{2}{*}{ No dust } & Fluorescent & $2.6 \pm 0.8(0.03)$ & $3.1 \pm 0.4(0.00)$ & $7.3 \pm 0.6(0.00)$ & $9.4 \pm 1.3(0.00)$ \\
& LED & $3.8 \pm 1.3(0.04)$ & $5.2 \pm 1.6(0.03)$ & $10.4 \pm 3.4(0.03)$ & $18.7 \pm 2.0(0.00)$ \\
\hline \multirow{2}{*}{ Dust $\left(6.9 \mathrm{mg} \cdot \mathrm{cm}^{-2}\right)$} & Fluorescent & $3.1 \pm 0.5(0.00)$ & $4.2 \pm 2.2(0.07)$ & $6.2 \pm 0.8(0.00)$ & $9.2 \pm 2.0(0.01)$ \\
& LED & $4.0 \pm 1.0(0.02)$ & $5.0 \pm 1.8(0.03)$ & $11.1 \pm 1.9(0.01)$ & $16.2 \pm 3.2(0.01)$ \\
\hline \multirow{2}{*}{ Dust $\left(11.0 \mathrm{mg} \cdot \mathrm{cm}^{-2}\right)$} & Fluorescent & $1.1 \pm 1.9(0.42)$ & $3.3 \pm 5.8(0.43)$ & $5.1 \pm 1.7(0.03)$ & $7.2 \pm 0.8(0.00)$ \\
& LED & $4.2 \pm 2.0(0.07)$ & $3.1 \pm 0.4(0.00)$ & $8.1 \pm 1.5(0.01)$ & $9.2 \pm 0.9(0.00)$ \\
\hline \multirow{2}{*}{ Dust $\left(16.3 \mathrm{mg} \cdot \mathrm{cm}^{-2}\right)$} & Fluorescent & $0.9 \pm 1.5(0.42)$ & $2.0 \pm 1.7(0.19)$ & $0.9 \pm 1.6(0.42)$ & $4.0 \pm 3.5(0.18)$ \\
& LED & $2.0 \pm 1.7(0.17)$ & $2.8 \pm 2.6(0.20)$ & $5.1 \pm 1.7(0.03)$ & $6.7 \pm 3.4(0.08)$ \\
\hline
\end{tabular}

Table A4. $\mathrm{NH}_{3}$ mitigation under the different dust levels at a relative humidity of $40 \%$ and $60 \%$. Value in the table report $\%$ reduction \pm standard deviation ( $p$-value).

\begin{tabular}{cccccc}
\hline \multicolumn{2}{c}{ Relative Humidity } & \multicolumn{2}{c}{$\mathbf{4 0 \%}$} & \multicolumn{2}{c}{$\mathbf{6 0 \%}$} \\
\hline \multicolumn{2}{c}{ Treatment Time } & $\mathbf{4 0} \mathbf{~ s}$ & $\mathbf{2 0 0} \mathbf{s}$ & $\mathbf{4 0 ~ s}$ & $\mathbf{2 0 0 ~ s}$ \\
\hline \multirow{2}{*}{ No dust } & Fluorescent & $5.0 \pm 1.5(0.03)$ & $5.3 \pm 2.4(0.05)$ & $3.1 \pm 0.4(0.01)$ & $3.2 \pm 0.4(0.00)$ \\
& LED & $7.3 \pm 1.2(0.00)$ & $13.5 \pm 2.6(0.01)$ & $5.1 \pm 3.1(0.08)$ & $6.2 \pm 0.6(0.00)$ \\
\hline \multirow{2}{*}{ Dust $\left(6.9 \mathrm{mg} \cdot \mathrm{cm}^{-2}\right)$} & Fluorescent & $3.1 \pm 3.4(0.25)$ & $4.3 \pm 2.1(0.08)$ & $2.0 \pm 1.7(0.18)$ & $2.9 \pm 2.7(0.20)$ \\
& LED & $8.4 \pm 4.3(0.07)$ & $10.5 \pm 2.7(0.02)$ & $5.1 \pm 1.7(0.03)$ & $6.8 \pm 3.6(0.08)$ \\
\hline \multirow{2}{*}{ Dust $\left(11.0 \mathrm{mg} \cdot \mathrm{cm}^{-2}\right)$} & Fluorescent & $2.0 \pm 1.8(0.19)$ & $2.9 \pm 2.7(0.21)$ & $3.2 \pm 3.2(0.23)$ & $1.8 \pm 3.1(0.82)$ \\
& LED & $6.2 \pm 3.4(0.08)$ & $5.1 \pm 1.7(0.03)$ & $4.0 \pm 1.1(0.02)$ & $6.2 \pm 0.6(0.00)$ \\
\hline \multirow{2}{*}{ Dust $\left(16.3 \mathrm{mg} \cdot \mathrm{cm}^{-2}\right)$} & Fluorescent & $0.0 \pm 0.0(1.00)$ & $1.1 \pm 1.9(0.42)$ & $0.0 \pm 0.0(1.00)$ & $0.0 \pm 0.0(1.00)$ \\
& LED & $2.3 \pm 4.0(0.47)$ & $5.3 \pm 2.4(0.05)$ & $4.3 \pm 4.9(0.27)$ & $4.0 \pm 1.3(0.03)$ \\
\hline
\end{tabular}


Table A5. $\mathrm{CO}_{2}$ mitigation under the different dust levels at a relative humidity of $12 \%$. Values in the table report \% reduction \pm standard deviation ( $p$-value) and are an average between treatments of $\mathrm{NH}_{3}$ and $\mathrm{H}_{2} \mathrm{~S}$ standard gases. Bold font signifies statistical significance.

\begin{tabular}{cccc}
\hline \multirow{2}{*}{ Dust level } & $\begin{array}{c}\text { Type of } \\
\text { UV Lamp }\end{array}$ & $\begin{array}{c}\text { Photocatalysis } \\
\text { at A Treatment Time of 40 s } \\
\left(\mathbf{U V}+\mathrm{TiO}_{\mathbf{2}} \mathbf{)}\right.\end{array}$ & $\begin{array}{c}\text { Photocatalysis } \\
\text { at A Treatment Time of 200 s } \\
\left(\mathbf{U V}+\mathrm{TiO}_{\mathbf{2}} \mathbf{)}\right.\end{array}$ \\
\hline \multirow{2}{*}{ No dust } & Fluorescent & $1.4 \pm 3.4(0.57)$ & $6.5 \pm 6.2(0.23)$ \\
& LED & $4.2 \pm 3.3(0.17)$ & $3.8 \pm \mathbf{0 . 7}(\mathbf{0 . 0 1})$ \\
\hline \multirow{2}{*}{ Dust $\left(6.9 \mathrm{mg} \cdot \mathrm{cm}^{-2}\right)$} & Fluorescent & $1.5 \pm 4.1(0.56)$ & $0.9 \pm 15.2(0.90)$ \\
& LED & $-0.7 \pm 6.6(0.96)$ & $3.5 \pm 7.7(0.50)$ \\
\hline \multirow{2}{*}{ Dust $\left(11.0 \mathrm{mg} \cdot \mathrm{cm}^{-2}\right)$} & Fluorescent & $3.5 \pm 7.7(0.50)$ & $2.7 \pm 7.7(0.55)$ \\
& LED & $0.5 \pm 4.4(0.91)$ & $-1.3 \pm 3.3(0.54)$ \\
\hline \multirow{2}{*}{ Dust $\left(16.3 \mathrm{mg} \cdot \mathrm{cm}^{-2}\right)$} & Fluorescent & $4.2 \pm 3.5(0.17)$ & $-2.5 \pm 7.1(0.59)$ \\
& LED & $0.4 \pm 8.8(0.65)$ & $0.7 \pm 5.6(0.90)$ \\
\hline
\end{tabular}

Table A6. $\mathrm{N}_{2} \mathrm{O}$ mitigation under different light types and relative humidity at a treatment time of $40 \mathrm{~s}$. Values in the table report \% reduction \pm standard deviation ( $p$-value) and are an average between treatments of $\mathrm{NH}_{3}$ and $\mathrm{H}_{2} \mathrm{~S}$ standard gases. Bold font signifies statistical significance.

\begin{tabular}{ccccc}
\hline $\begin{array}{c}\text { Relative } \\
\text { Humidity }\end{array}$ & $\begin{array}{c}\text { Type of } \\
\text { UV Lamp }\end{array}$ & $\begin{array}{c}\text { Direct Photolysis } \\
\text { (UV only) }\end{array}$ & $\begin{array}{c}\text { Photocatalysis } \\
\text { (UV + } \mathbf{T i O}_{\mathbf{2}} \text { ) }\end{array}$ & $\begin{array}{c}\text { Adsorption } \\
\text { (to } \mathbf{T i O}_{\mathbf{2}} \text { ) }\end{array}$ \\
\hline \multirow{2}{*}{ Dry } & Fluorescent & $1.6 \pm 2.0$ & $4.8 \pm 4.9(0.14)$ & $3.0 \pm 1.5$ \\
& LED & $2.7 \pm 1.2$ & $\mathbf{6 . 5} \pm \mathbf{2 . 5}(\mathbf{0 . 0 2})$ & $-0.6 \pm 3.5$ \\
\hline \multirow{2}{*}{$12 \%$} & Fluorescent & $2.1 \pm 2.1$ & $3.1 \pm 2.9(0.06)$ & $1.8 \pm 3.5$ \\
& LED & $3.3 \pm 1.8$ & $9.0 \pm 5.2(0.05)$ & $3.2 \pm 10.9$ \\
\hline \multirow{2}{*}{$40 \%$} & Fluorescent & $1.8 \pm 0.8$ & $\mathbf{3 . 4} \pm \mathbf{0 . 2}(\mathbf{0 . 0 0 )}$ & $1.6 \pm 3.2$ \\
& LED & $3.1 \pm 2.1$ & $\mathbf{6 . 8} \pm \mathbf{1 . 7}(\mathbf{0 . 0 1})$ & $-1.4 \pm 2.1$ \\
\hline \multirow{2}{*}{$60 \%$} & Fluorescent & $2.5 \pm 3.3$ & $\mathbf{2 . 8} \pm \mathbf{0 . 7}(\mathbf{0 . 0 3})$ & $-1.0 \pm 3.5$ \\
& LED & $3.7 \pm 2.4$ & $5.2 \pm 3.3(0.07)$ & $2.2 \pm 2.7$ \\
\hline \multirow{2}{*}{ Average } & Fluorescent & $2.0 \pm 1.9$ & $3.5 \pm 2.7$ & $1.8 \pm 2.9$ \\
& LED & $3.2 \pm 1.7$ & $6.7 \pm 3.4$ & $0.9 \pm 5.5$ \\
\hline
\end{tabular}

Table A7. $\mathrm{N}_{2} \mathrm{O}$ mitigation under different light types and relative humidity at a treatment time of $200 \mathrm{~s}$. Values in the table report \% reduction \pm standard deviation ( $p$-value) and are an average between treatments of $\mathrm{NH}_{3}$ and $\mathrm{H}_{2} \mathrm{~S}$ standard gases. Bold font signifies statistical significance.

\begin{tabular}{|c|c|c|c|c|}
\hline $\begin{array}{l}\text { Relative } \\
\text { Humidity }\end{array}$ & $\begin{array}{l}\text { Type of } \\
\text { UV Lamp }\end{array}$ & $\begin{array}{l}\text { Direct Photolysis } \\
\text { (UV only) }\end{array}$ & $\begin{array}{c}\text { Photocatalysis } \\
\left(\mathrm{UV}+\mathrm{TiO}_{2}\right)\end{array}$ & $\begin{array}{c}\text { Adsorption } \\
\left.\text { (to } \mathrm{TiO}_{2}\right)\end{array}$ \\
\hline \multirow{2}{*}{ Dry } & Fluorescent & $1.3 \pm 1.5$ & $3.7 \pm 1.8(0.03)$ & $2.5 \pm 2.8$ \\
\hline & LED & $3.3 \pm 1.2(0.04)$ & $5.1 \pm 1.0(0.00)$ & $4.4 \pm 2.8$ \\
\hline \multirow{2}{*}{$12 \%$} & Fluorescent & $1.8 \pm 1.6$ & $3.3 \pm 2.1(0.07)$ & $1.4 \pm 1.7$ \\
\hline & LED & $6.5 \pm 1.7(0.02)$ & $9.5 \pm 3.3(0.02)$ & $0.8 \pm 5.2$ \\
\hline \multirow{2}{*}{$40 \%$} & Fluorescent & $1.3 \pm 1.1$ & $3.0 \pm 2.3(0.06)$ & $0.2 \pm 0.4$ \\
\hline & LED & $4.9 \pm 4.4$ & $10.6 \pm 6.6(0.06)$ & $3.1 \pm 4.0$ \\
\hline \multirow{2}{*}{$60 \%$} & Fluorescent & $1.0 \pm 0.8$ & $5.6 \pm 3.8(0.08)$ & $-2.1 \pm 3.5$ \\
\hline & LED & $0.8 \pm 0.5$ & $5.0 \pm 0.9(0.00)$ & $2.2 \pm 1.4$ \\
\hline \multirow{2}{*}{ Average } & Fluorescent & $1.7 \pm 1.2$ & $3.9 \pm 2.5$ & $0.5 \pm 2.7$ \\
\hline & LED & $3.9 \pm 3.0$ & $7.5 \pm 4.3$ & $2.6 \pm 3.4$ \\
\hline
\end{tabular}


Table A8. $\mathrm{N}_{2} \mathrm{O}$ mitigation under the different dust levels at a treatment time of $200 \mathrm{~s}$ in direct photolysis. Values in the table report \% reduction \pm standard deviation ( $p$-value) and are an average between treatments of $\mathrm{NH}_{3}$ and $\mathrm{H}_{2} \mathrm{~S}$ standard gases. Bold font signifies statistical significance.

\begin{tabular}{cccccc}
\hline \multicolumn{2}{c}{ Relative Humidity } & Dry & $\mathbf{1 2} \%$ & $\mathbf{4 0} \%$ & $\mathbf{6 0} \%$ \\
\hline \multirow{2}{*}{ No Dust } & Fluorescent & $1.3 \pm 1.5(0.32)$ & $1.8 \pm 1.6(0.20)$ & $1.3 \pm 1.1(0.15)$ & $1.0 \pm 0.8(0.16)$ \\
& LED & $\mathbf{3 . 3} \pm \mathbf{1 . 2 ( 0 . 0 4 )}$ & $\mathbf{6 . 5} \pm \mathbf{1 . 7 ( 0 . 0 2 )}$ & $4.9 \pm 4.4(0.15)$ & $0.8 \pm 0.5(0.12)$ \\
\hline \multirow{2}{*}{ Dust $\left(6.9 \mathrm{mg} \cdot \mathrm{cm}^{-2}\right)$} & Fluorescent & $1.0 \pm 0.5(0.08)$ & $4.1 \pm 6.9(0.41)$ & $4.4 \pm 4.3(0.23)$ & $3.5 \pm 6.0(0.41)$ \\
& LED & $\mathbf{1 . 6} \pm \mathbf{0 . 4 ( 0 . 0 3 )}$ & $6.1 \pm 3.0(0.08)$ & $\mathbf{5 . 3} \pm \mathbf{1 . 7 ( 0 . 0 3 )}$ & $5.2 \pm 3.3(0.13)$ \\
\hline \multirow{2}{*}{ Dust $\left(11.0 \mathrm{mg} \cdot \mathrm{cm}^{-2}\right)$} & Fluorescent & $1.1 \pm 1.8(0.40)$ & $4.2 \pm 3.0(0.08)$ & $5.0 \pm 9.6(0.45)$ & $\mathbf{3 . 2} \pm \mathbf{1 . 1}(\mathbf{0 . 0 3})$ \\
& LED & $2.8 \pm 1.4(0.06)$ & $4.0 \pm 1.7(0.06)$ & $4.8 \pm 2.5(0.05)$ & $5.9 \pm 5.0(0.18)$ \\
\hline \multirow{2}{*}{ Dust $\left(16.3 \mathrm{mg} \cdot \mathrm{cm}^{-2}\right)$} & Fluorescent & $2.5 \pm 2.1(0.18)$ & $2.4 \pm 2.1(0.22)$ & $7.2 \pm 6.3(0.19)$ & $4.8 \pm 3.6(0.10)$ \\
& LED & $1.4 \pm 0.8(0.10)$ & $4.2 \pm 7.0(0.40)$ & $5.0 \pm 9.5(0.45)$ & $7.1 \pm 6.3(0.19)$ \\
\hline
\end{tabular}

Table A9. $\mathrm{N}_{2} \mathrm{O}$ mitigation under the different dust levels at a relative humidity of dry and $12 \%$ in photocatalysis. Values in the table report $\%$ reduction \pm standard deviation ( $p$-value) and are an average between treatments of $\mathrm{NH}_{3}$ and $\mathrm{H}_{2} \mathrm{~S}$ standard gases. Bold font signifies statistical significance.

\begin{tabular}{|c|c|c|c|c|c|}
\hline \multirow{2}{*}{\multicolumn{2}{|c|}{$\begin{array}{c}\text { Relative Humidity } \\
\text { Treatment Time }\end{array}$}} & \multicolumn{2}{|c|}{ Dry } & \multicolumn{2}{|c|}{$12 \%$} \\
\hline & & \multirow{3}{*}{$\begin{array}{c}40 \mathrm{~s} \\
4.8 \pm 4.9(0.14) \\
\mathbf{6 . 5} \pm 2.5(\mathbf{0 . 0 2})\end{array}$} & \multirow{3}{*}{$\begin{array}{c}200 \mathrm{~s} \\
3.7 \pm 1.8(0.03) \\
5.1 \pm 1.0(0.00)\end{array}$} & \multirow{3}{*}{$\begin{array}{c}40 \mathrm{~s} \\
3.1 \pm 2.9(0.06) \\
9.0 \pm 5.2(0.05)\end{array}$} & \multirow{3}{*}{$\begin{array}{c}200 \mathrm{~s} \\
3.3 \pm 2.1(0.07) \\
9.5 \pm 3.3(0.02)\end{array}$} \\
\hline & Fluorescent & & & & \\
\hline No Dust & LED & & & & \\
\hline \multirow{2}{*}{ Dust $\left(6.9 \mathrm{mg} \cdot \mathrm{cm}^{-2}\right)$} & Fluorescent & $8.5 \pm 4.3(0.09)$ & $3.1 \pm 2.2(0.14)$ & $10.5 \pm 3.9(0.06)$ & $3.2 \pm 0.9(0.03)$ \\
\hline & LED & $4.7 \pm 5.9(0.30)$ & $4.2 \pm 2.0(0.04)$ & $5.1 \pm 3.4(0.12)$ & $11.2 \pm 2.1(0.04)$ \\
\hline \multirow{2}{*}{ Dust $\left(11.0 \mathrm{mg} \cdot \mathrm{cm}^{-2}\right)$} & Fluorescent & $4.1 \pm 3.1(0.16)$ & $5.3 \pm 2.2(0.05)$ & $4.1 \pm 3.7(0.20)$ & $1.0 \pm 2.3(0.53)$ \\
\hline & LED & $5.0 \pm 1.6(0.04)$ & $4.2 \pm 3.3(0.16)$ & $3.7 \pm 3.2(0.18)$ & $4.2 \pm 3.7(0.20)$ \\
\hline \multirow{2}{*}{ Dust $\left(16.3 \mathrm{mg} \cdot \mathrm{cm}^{-2}\right)$} & Fluorescent & $3.6 \pm 5.5(0.35)$ & $5.3 \pm 3.9(0.14)$ & $8.9 \pm 6.2(0.14)$ & $3.3 \pm 6.9(0.41)$ \\
\hline & LED & $5.7 \pm 5.6(0.23)$ & $2.8 \pm 0.5(0.00)$ & $3.4 \pm 0.3(0.01)$ & $4.7 \pm 2.0(0.04)$ \\
\hline
\end{tabular}

Table A10. $\mathrm{N}_{2} \mathrm{O}$ mitigation under the different dust levels at a relative humidity of $40 \%$ and $60 \%$ in photocatalysis. Values in the table report $\%$ reduction \pm standard deviation ( $p$-value) and are an average between treatments of $\mathrm{NH}_{3}$ and $\mathrm{H}_{2} \mathrm{~S}$ standard gases. Bold font signifies statistical significance.

\begin{tabular}{|c|c|c|c|c|c|}
\hline \multirow{2}{*}{\multicolumn{2}{|c|}{$\begin{array}{c}\text { Relative Humidity } \\
\text { Treatment Time }\end{array}$}} & \multicolumn{2}{|c|}{$40 \%$} & \multicolumn{2}{|c|}{$60 \%$} \\
\hline & & $40 \mathrm{~s}$ & $200 \mathrm{~s}$ & $40 \mathrm{~s}$ & $200 \mathrm{~s}$ \\
\hline \multirow{2}{*}{ No Dust } & Fluorescent & $3.4 \pm 0.2(0.00)$ & $3.0 \pm 2.3(0.06)$ & $2.8 \pm 0.7(0.03)$ & $5.6 \pm 3.8(0.08)$ \\
\hline & LED & $6.8 \pm 1.7(0.01)$ & $10.6 \pm 6.6(0.06)$ & $5.2 \pm 3.3(0.07)$ & $5.0 \pm 0.9(0.00)$ \\
\hline \multirow{2}{*}{ Dust $\left(6.9 \mathrm{mg} \cdot \mathrm{cm}^{-2}\right)$} & Fluorescent & $4.6 \pm 2.0(0.07)$ & $6.2 \pm 1.8(0.04)$ & $2.4 \pm 6.2(0.54)$ & $2.1 \pm 6.2(0.67)$ \\
\hline & LED & $5.3 \pm 2.1(0.05)$ & $7.9 \pm 2.3(0.01)$ & $4.5 \pm 2.3(0.09)$ & $7.1 \pm 6.4(0.20)$ \\
\hline \multirow{2}{*}{ Dust $\left(11.0 \mathrm{mg} \cdot \mathrm{cm}^{-2}\right)$} & Fluorescent & $11.3 \pm 7.2(0.13)$ & $1.0 \pm 2.3(0.52)$ & $3.3 \pm 3.1(0.20)$ & $5.6 \pm 2.4(0.05)$ \\
\hline & LED & $2.8 \pm 3.0(0.22)$ & $5.3 \pm 3.9(0.14)$ & $3.6 \pm 5.5(0.37)$ & $3.7 \pm 6.3(0.41)$ \\
\hline \multirow{2}{*}{ Dust $\left(16.3 \mathrm{mg} \cdot \mathrm{cm}^{-2}\right)$} & Fluorescent & $7.4 \pm 6.2(0.20)$ & $3.9 \pm 5.9(0.36)$ & $5.1 \pm 3.3(0.12)$ & $6.8 \pm 6.8(0.18)$ \\
\hline & LED & $2.4 \pm 3.2(0.32)$ & $1.0 \pm 2.2(0.52)$ & $1.4 \pm 1.3(0.19)$ & $3.8 \pm 5.8(0.36)$ \\
\hline
\end{tabular}


Table A11. $\mathrm{O}_{3}$ mitigation under different light types and relative humidity at a treatment time of 40 $\mathrm{s}$. Values in the table report \% reduction \pm standard deviation ( $p$-value) and are an average between treatments of $\mathrm{NH}_{3}$ and $\mathrm{H}_{2} \mathrm{~S}$ standard gases. Bold font signifies statistical significance.

\begin{tabular}{|c|c|c|c|c|}
\hline $\begin{array}{l}\text { Relative } \\
\text { Humidity }\end{array}$ & $\begin{array}{l}\text { Type of } \\
\text { UV Lamp }\end{array}$ & $\begin{array}{l}\text { Direct Photolysis } \\
\text { (UV only) }\end{array}$ & $\begin{array}{l}\text { Photocatalysis } \\
\left(\mathrm{UV}+\mathrm{TiO}_{2}\right)\end{array}$ & $\begin{array}{l}\text { Adsorption } \\
\text { (to } \mathrm{TiO}_{2} \text { ) }\end{array}$ \\
\hline \multirow{2}{*}{ Dry } & Fluorescent & $14.9 \pm 5.4(0.05)$ & $22.3 \pm 16.2(0.07)$ & $5.3 \pm 9.1$ \\
\hline & LED & $16.1 \pm 12.1(0.16)$ & $29.7 \pm 2.6(0.00)$ & $2.7 \pm 21.6$ \\
\hline \multirow{2}{*}{$12 \%$} & Fluorescent & $11.8 \pm 10.7(0.19)$ & $21.2 \pm 13.5(0.06)$ & $5.1 \pm 5.6$ \\
\hline & LED & $26.0 \pm 11.6(0.08)$ & $37.0 \pm 6.9(0.03)$ & $-1.1 \pm 1.9$ \\
\hline \multirow{2}{*}{$40 \%$} & Fluorescent & $14.9 \pm 10.6(0.11)$ & $27.4 \pm 17.1(0.15)$ & $4.2 \pm 7.2$ \\
\hline & LED & $23.5 \pm 4.2(0.00)$ & $36.0 \pm 7.1(0.02)$ & $1.8 \pm 16.1$ \\
\hline \multirow{2}{*}{$60 \%$} & Fluorescent & $11.3 \pm 4.9(0.06)$ & $21.6 \pm 2.4(0.00)$ & $8.9 \pm 7.7$ \\
\hline & LED & $31.5 \pm 14.1(0.07)$ & $27.6 \pm 16.0(0.17)$ & $4.2 \pm 7.2$ \\
\hline \multirow{2}{*}{ Average } & Fluorescent & $13.2 \pm 7.3$ & $23.1 \pm 12.5$ & $5.9 \pm 6.7$ \\
\hline & LED & $24.3 \pm 11.1$ & $32.6 \pm 9.4$ & $1.9 \pm 12.1$ \\
\hline
\end{tabular}

Table A12. $\mathrm{O}_{3}$ mitigation under different light types and relative humidity at $200 \mathrm{~s}$. Values report $\%$ reduction \pm st. dev. (p-value) and are an average between treatments of $\mathrm{NH}_{3}$ and $\mathrm{H}_{2} \mathrm{~S}$. Bold font signifies statistical significance.

\begin{tabular}{|c|c|c|c|c|}
\hline $\begin{array}{l}\text { Relative } \\
\text { Humidity }\end{array}$ & $\begin{array}{c}\text { Type of } \\
\text { UV Lamp }\end{array}$ & $\begin{array}{l}\text { Direct Photolysis } \\
\text { (UV only) }\end{array}$ & $\begin{array}{c}\text { Photocatalysis } \\
\left(\mathrm{UV}+\mathrm{TiO}_{2}\right)\end{array}$ & $\begin{array}{c}\text { Adsorption } \\
\text { (to } \mathrm{TiO}_{2} \text { ) }\end{array}$ \\
\hline \multirow{2}{*}{ Dry } & Fluorescent & $13.3 \pm 5.2(0.05)$ & $22.5 \pm 5.4(0.04)$ & $6.0 \pm 7.4$ \\
\hline & LED & $12.8 \pm 3.1(0.01)$ & $28.7 \pm 3.7(0.00)$ & $3.0 \pm 2.6$ \\
\hline \multirow{2}{*}{$12 \%$} & Fluorescent & $12.4 \pm 3.8(0.03)$ & $23.7 \pm 2.6(0.00)$ & $2.5 \pm 5.6$ \\
\hline & LED & $12.9 \pm 0.8(0.00)$ & $48.4 \pm 5.3(0.00)$ & $5.4 \pm 6.1$ \\
\hline \multirow{2}{*}{$40 \%$} & Fluorescent & $10.8 \pm 6.1(0.09)$ & $21.8 \pm 5.3(0.00)$ & $7.0 \pm 9.1$ \\
\hline & LED & $8.9 \pm 4.7(0.09)$ & $26.0 \pm 5.2(0.01)$ & $5.0 \pm 1.6$ \\
\hline \multirow{2}{*}{$60 \%$} & Fluorescent & $18.2 \pm 10.4(0.11)$ & $23.6 \pm 0.7(0.00)$ & $6.1 \pm 3.5$ \\
\hline & LED & $24.1 \pm 7.9(0.03)$ & $37.5 \pm 5.1(0.00)$ & $1.8 \pm 5.9$ \\
\hline \multirow{2}{*}{ Average } & Fluorescent & $13.7 \pm 6.5$ & $22.9 \pm 3.7$ & $5.4 \pm 6.0$ \\
\hline & LED & $14.7 \pm 7.3$ & $35.2 \pm 10.0$ & $3.3 \pm 4.1$ \\
\hline
\end{tabular}

Table A13. $\mathrm{O}_{3}$ mitigation under the different dust levels at a relative humidity of dry and $12 \%$ in direct photolysis. Value in the table report \% reduction \pm standard deviation ( $p$-value) and are an average between treatments of $\mathrm{NH}_{3}$ and $\mathrm{H}_{2} \mathrm{~S}$ standard gases. Bold font signifies statistical significance.

\begin{tabular}{|c|c|c|c|c|c|}
\hline \multirow{2}{*}{\multicolumn{2}{|c|}{$\begin{array}{c}\text { Relative Humidity } \\
\text { Treatment Time }\end{array}$}} & \multicolumn{2}{|c|}{ Dry } & \multicolumn{2}{|c|}{$12 \%$} \\
\hline & & $40 \mathrm{~s}$ & $200 \mathrm{~s}$ & $40 \mathrm{~s}$ & $200 \mathrm{~s}$ \\
\hline \multirow{2}{*}{ No dust } & Fluorescent & $14.9 \pm 5.4(0.05)$ & $13.3 \pm 5.2(0.05)$ & $11.8 \pm 10.7(0.19)$ & $12.4 \pm 3.8(0.03)$ \\
\hline & LED & $16.1 \pm 12.1(0.16)$ & $12.8 \pm 3.1(0.01)$ & $26.0 \pm 11.6(0.08)$ & $12.9 \pm 0.8(0.00)$ \\
\hline \multirow{2}{*}{ Dust $\left(6.9 \mathrm{mg} \cdot \mathrm{cm}^{-2}\right)$} & Fluorescent & $11.4 \pm 5.2(0.05)$ & $21.0 \pm 12.8(0.10)$ & $12.1 \pm 8.5(0.15)$ & $13.1 \pm 5.7(0.06)$ \\
\hline & LED & $14.7 \pm 9.5(0.12)$ & $19.8 \pm 8.9(0.07)$ & $38.0 \pm 16.9(0.05)$ & $15.6 \pm 8.5(0.09)$ \\
\hline \multirow{2}{*}{ Dust $\left(11.0 \mathrm{mg} \cdot \mathrm{cm}^{-2}\right)$} & Fluorescent & $14.4 \pm 1.4(0.00)$ & $19.0 \pm 11.6(0.11)$ & $16.7 \pm 8.5(0.08)$ & $18.4 \pm 5.9(0.03)$ \\
\hline & LED & $22.5 \pm 12.3(0.09)$ & $16.0 \pm 0.8(0.00)$ & $25.5 \pm 11.5(0.06)$ & $26.3 \pm 10.4(0.05)$ \\
\hline \multirow{2}{*}{ Dust $\left(16.3 \mathrm{mg} \cdot \mathrm{cm}^{-2}\right)$} & Fluorescent & $16.1 \pm 11.1(0.12)$ & $21.2 \pm 10.5(0.09)$ & $17.8 \pm 8.8(0.08)$ & $11.6 \pm 6.6(0.09)$ \\
\hline & LED & $15.6 \pm 10.1(0.12)$ & $29.4 \pm 22.0(0.19)$ & $21.8 \pm 6.6(0.03)$ & $25.8 \pm 8.4(0.04)$ \\
\hline
\end{tabular}


Table A14. $\mathrm{O}_{3}$ mitigation under the different dust levels at a relative humidity of $40 \%$ and $60 \%$ in photolysis. Value in the table report \% reduction \pm standard deviation ( $p$-value) and are an average between treatments of $\mathrm{NH}_{3}$ and $\mathrm{H}_{2} \mathrm{~S}$ standard gases. Bold font signifies statistical significance.

\begin{tabular}{|c|c|c|c|c|c|}
\hline \multirow{2}{*}{\multicolumn{2}{|c|}{$\begin{array}{c}\text { Relative Humidity } \\
\text { Treatment Time }\end{array}$}} & \multicolumn{2}{|c|}{$40 \%$} & \multicolumn{2}{|c|}{$60 \%$} \\
\hline & & $40 \mathrm{~s}$ & $200 \mathrm{~s}$ & $40 \mathrm{~s}$ & $200 \mathrm{~s}$ \\
\hline \multirow{2}{*}{ No Dust } & Fluorescent & $14.9 \pm 10.6(0.11)$ & $10.8 \pm 6.1(0.09)$ & $11.3 \pm 4.9(0.06)$ & $18.2 \pm 10.4(0.11)$ \\
\hline & LED & $23.5 \pm 4.2(0.00)$ & $8.9 \pm 4.7(0.09)$ & $31.5 \pm 14.1(0.07)$ & $24.1 \pm 7.9(0.03)$ \\
\hline \multirow{2}{*}{ Dust $\left(6.9 \mathrm{mg} \cdot \mathrm{cm}^{-2}\right)$} & Fluorescent & $20.6 \pm 9.7(0.06)$ & $13.8 \pm 3.3(0.02)$ & $29.0 \pm 4.7(0.02)$ & $13.6 \pm 7.1(0.09)$ \\
\hline & LED & $19.1 \pm 3.7(0.00)$ & $15.4 \pm 2.2(0.00)$ & $18.3 \pm 2.5(0.00)$ & $17.9 \pm 9.5(0.09)$ \\
\hline \multirow{2}{*}{ Dust $\left(11.0 \mathrm{mg} \cdot \mathrm{cm}^{-2}\right)$} & Fluorescent & $10.7 \pm 10.0(0.20)$ & $14.2 \pm 8.7(0.11)$ & $18.0 \pm 9.1(0.08)$ & $20.6 \pm 11.0(0.10)$ \\
\hline & LED & $18.1 \pm 6.4(0.06)$ & $21.9 \pm 3.2(0.00)$ & $14.9 \pm 8.0(0.09)$ & $22.1 \pm 6.6(0.03)$ \\
\hline \multirow{2}{*}{ Dust $\left(16.3 \mathrm{mg} \cdot \mathrm{cm}^{-2}\right)$} & Fluorescent & $16.2 \pm 6.0(0.03)$ & $20.8 \pm 19.6(0.21)$ & $17.5 \pm 18.9(0.27)$ & $21.4 \pm 13.3(0.14)$ \\
\hline & LED & $18.1 \pm 7.4(0.05)$ & $13.5 \pm 4.74(0.03)$ & $18.9 \pm 5.7(0.03)$ & $18.0 \pm 3.4(0.02)$ \\
\hline
\end{tabular}

Table A15. $\mathrm{O}_{3}$ mitigation under the different dust levels at a relative humidity of dry and $12 \%$ in photocatalysis. Value in the table report \% reduction \pm standard deviation ( $p$-value) and are an average between treatments of $\mathrm{NH}_{3}$ and $\mathrm{H}_{2} \mathrm{~S}$ standard gases. Bold font signifies statistical significance.

\begin{tabular}{|c|c|c|c|c|c|}
\hline \multirow{2}{*}{\multicolumn{2}{|c|}{$\begin{array}{c}\text { Relative Humidity } \\
\text { Treatment Time }\end{array}$}} & \multicolumn{2}{|c|}{ Dry } & \multicolumn{2}{|c|}{$12 \%$} \\
\hline & & \multirow{3}{*}{$\begin{array}{c}40 \mathrm{~s} \\
22.3 \pm 16.2(0.07) \\
29.7 \pm 2.6(0.00)\end{array}$} & \multirow{3}{*}{$\begin{array}{c}200 \mathrm{~s} \\
22.5 \pm 5.4(0.04) \\
28.7 \pm 3.7(0.00)\end{array}$} & \multirow{3}{*}{$\begin{array}{c}40 \mathrm{~s} \\
21.2 \pm 13.5(0.06) \\
37.0 \pm 6.9(0.03)\end{array}$} & \multirow{3}{*}{$\begin{array}{c}200 \mathrm{~s} \\
23.7 \pm 2.6(0.00) \\
48.4 \pm 5.3(0.00)\end{array}$} \\
\hline & Fluorescent & & & & \\
\hline No dust & LED & & & & \\
\hline \multirow{2}{*}{ Dust $\left(6.9 \mathrm{mg} \cdot \mathrm{cm}^{-2}\right)$} & Fluorescent & $18.4 \pm 3.0(0.01)$ & $32.8 \pm 5.6(0.01)$ & $26.7 \pm 9.6(0.05)$ & $36.9 \pm 2.8(0.00)$ \\
\hline & LED & $21.7 \pm 9.5(0.06)$ & $38.1 \pm 7.8(0.02)$ & $35.3 \pm 7.2(0.01)$ & $29.0 \pm 1.6(0.00)$ \\
\hline \multirow{2}{*}{ Dust $\left(11.0 \mathrm{mg} \cdot \mathrm{cm}^{-2}\right)$} & Fluorescent & $27.6 \pm 13.9(0.08)$ & $33.1 \pm 6.3(0.01)$ & $33.7 \pm 11.1(0.03)$ & $34.0 \pm 10.0(0.03)$ \\
\hline & LED & $28.4 \pm 8.0(0.03)$ & $40.5 \pm 3.7(0.00)$ & $44.9 \pm 1.8(0.00)$ & $44.1 \pm 11.5(0.03)$ \\
\hline \multirow{2}{*}{ Dust $\left(16.3 \mathrm{mg} \cdot \mathrm{cm}^{-2}\right)$} & Fluorescent & $27.5 \pm 8.8(0.03)$ & $36.6 \pm 7.1(0.02)$ & $26.5 \pm 2.9(0.00)$ & $37.7 \pm 6.6(0.01)$ \\
\hline & LED & $33.1 \pm 11.8(0.04)$ & $48.9 \pm 13.9(0.03)$ & $33.9 \pm 10.0(0.03)$ & $48.9 \pm 4.1(0.00)$ \\
\hline
\end{tabular}

Table A16. $\mathrm{O}_{3}$ mitigation under the different dust levels at a relative humidity of $40 \%$ and $60 \%$ in photocatalysis. Value in the table report $\%$ reduction \pm standard deviation ( $p$-value) and are an average between treatments of $\mathrm{NH}_{3}$ and $\mathrm{H}_{2} \mathrm{~S}$ standard gases. Bold font signifies statistical significance.

\begin{tabular}{cccccc}
\hline \multicolumn{2}{c}{ Relative Humidity } & \multicolumn{2}{c}{$40 \%$} & \multicolumn{2}{c}{$60 \%$} \\
\hline \multicolumn{2}{c}{ Treatment Time } & $40 \mathrm{~s}$ & $200 \mathrm{~s}$ & $40 \mathrm{~s}$ & $200 \mathrm{~s}$ \\
\hline \multirow{2}{*}{ No dust } & Fluorescent & $27.4 \pm 17.1(0.15)$ & $\mathbf{2 1 . 8} \pm 5.3(0.00)$ & $21.6 \pm 2.4(0.00)$ & $23.6 \pm 0.7(0.00)$ \\
& LED & $36.0 \pm 7.06(0.02)$ & $26.0 \pm 5.2(0.01)$ & $27.6 \pm 16.0(0.17)$ & $37.5 \pm 5.1(0.00)$ \\
\hline \multirow{2}{*}{ Dust $\left(6.9 \mathrm{mg} \cdot \mathrm{cm}^{-2}\right)$} & Fluorescent & $20.9 \pm 5.3(0.01)$ & $23.4 \pm 0.8(0.00)$ & $35.5 \pm 10.4(0.04)$ & $22.8 \pm 2.8(0.00)$ \\
& LED & $30.7 \pm 12.4(0.05)$ & $25.3 \pm 1.7(0.00)$ & $32.2 \pm 2.6(0.00)$ & $29.4 \pm 9.8(0.04)$ \\
\hline \multirow{2}{*}{ Dust $\left(11.0 \mathrm{mg} \cdot \mathrm{cm}^{-2}\right)$} & Fluorescent & $21.7 \pm 10.9(0.08)$ & $25.2 \pm 8.1(0.04)$ & $31.1 \pm 10.2(0.03)$ & $34.3 \pm 11.0(0.04)$ \\
& LED & $38.0 \pm 12.5(0.05)$ & $31.5 \pm 14.9(0.06)$ & $21.7 \pm 4.7(0.02)$ & $32.1 \pm 2.5(0.00)$ \\
\hline \multirow{2}{*}{ Dust $\left(16.3 \mathrm{mg} \cdot \mathrm{cm}^{-2}\right)$} & Fluorescent & $22.6 \pm 5.6(0.01)$ & $30.0 \pm 9.9(0.03)$ & $34.4 \pm 10.0(0.02)$ & $34.5 \pm 9.6(0.02)$ \\
& LED & $36.5 \pm 6.6(0.01)$ & $38.9 \pm 10.0(0.01)$ & $42.8 \pm 10.2(0.01)$ & $34.9 \pm 4.3(0.00)$ \\
\hline
\end{tabular}

\section{References}

1. Maurer, D.L.; Koziel, J.A. On-farm pilot-scale testing of black ultraviolet light and photocatalytic coating for mitigation of odor, odorous VOCs, and greenhouse gases. Chemosphere 2019, 221, 778-784. [CrossRef] [PubMed]

2. Buijsman, E.; Erisman, J.-W. Wet deposition of ammonium in Europe. J. Atmos. Chem. 1988, 6, $265-280$. [CrossRef]

3. Schiffman, S.S. Livestock odors: Implications for human health and well-being. J. Anim. Sci. 1998, 76, 1343-1355. [CrossRef]

4. Maurer, D.L.; Koziel, J.A.; Harmon, J.D.; Hoff, S.J.; Rieck-Hinz, A.M.; Andersen, D.S. Summary of performance data for technologies to control gaseous, odor, and particulate emissions from livestock operations: Air management practices assessment tool (AMPAT). Data Brief 2016, 7, 1413-1429. [CrossRef] 
5. Van der Heyden, C.; Demeyer, P.; Volcke, E.I. Mitigating emissions from pig and poultry housing facilities through air scrubbers and biofilters: State-of-the-art and perspectives. Biosyst. Eng. 2015, 134, 74-93. [CrossRef]

6. Maurer, D.; Koziel, J.; Kalus, K.; Andersen, D.; Opalinski, S. Pilot-scale testing of non-activated biochar for swine manure treatment and mitigation of ammonia, hydrogen sulfide, odorous volatile organic compounds (VOCs), and greenhouse gas emissions. Sustainability 2017, 9, 929. [CrossRef]

7. Maurer, D.L.; Koziel, J.A.; Bruning, K.; Parker, D.B. Farm-scale testing of soybean peroxidase and calcium peroxide for surficial swine manure treatment and mitigation of odorous VOCs, ammonia and hydrogen sulfide emissions. Atmos. Environ. 2017, 166, 467-478. [CrossRef]

8. Maurer, D.L.; Koziel, J.A.; Bruning, K.; Parker, D.B. Pilot-scale testing of renewable biocatalyst for swine manure treatment and mitigation of odorous VOCs, ammonia and hydrogen sulfide emissions. Atmos. Environ. 2017, 150, 313-321. [CrossRef]

9. Parker, D.B.; Hayes, M.; Brown-Brandl, T.; Woodbury, B.; Spiehs, M.; Koziel, J.A. Surface application of soybean peroxidase and calcium peroxide for reducing odorous VOC emissions from swine manure slurry. Appl. Eng. Agric. 2016, 32, 389-398. [CrossRef]

10. Cai, L.; Koziel, J.A.; Liang, Y.; Nguyen, A.T.; Xin, H. Evaluation of zeolite for control of odorants emissions from simulated poultry manure storage. J. Environ. Qual. 2007, 36, 184-193. [CrossRef]

11. Kalus, K.; Opaliński, S.; Maurer, D.; Rice, S.; Koziel, J.A.; Korczyński, M.; Dobrzański, Z.; Kołacz, R.; Gutarowska, B. Odour reducing microbial-mineral additive for poultry manure treatment. Front. Environ. Sci. Eng. 2017, 11, 7. [CrossRef]

12. Parker, D.B.; Pandrangi, S.; Greene, L.; Almas, L.; Cole, N.; Rhoades, M.; Koziel, J. Rate and frequency of urease inhibitor application for minimizing ammonia emissions from beef cattle feedyards. Trans. ASAE 2005, 48, 787-793. [CrossRef]

13. Parker, D.B.; Rhoades, M.B.; Koziel, J.A.; Baek, B.-H.; Waldrip, H.M.; Todd, R.W. Urease inhibitor for reducing ammonia emissions from an open-lot beef cattle feedyard in the Texas High Plains. Appl. Eng. Agric. 2016, 32, 823-832. [CrossRef]

14. Kalus, K.; Koziel, J.A.; Opaliński, S. A Review of Biochar Properties and Their Utilization in Crop Agriculture and Livestock Production. Appl. Sci. 2019, 9, 3494. [CrossRef]

15. Wi, J.; Lee, S.; Kim, E.; Lee, M.; Koziel, J.A.; Ahn, H. Evaluation of Semi-Continuous Pit Manure Recharge System Performance on Mitigation of Ammonia and Hydrogen Sulfide Emissions from a Swine Finishing Barn. Atmosphere 2019, 10, 170. [CrossRef]

16. Chen, L.; Hoff, S.; Cai, L.; Koziel, J.; Zelle, B. Evaluation of wood chip-based biofilters to reduce odor, hydrogen sulfide, and ammonia from swine barn ventilation air. J. Air Waste Manag. Assoc. 2009, 59, 520-530. [CrossRef] [PubMed]

17. Chen, L.; Hoff, S.J.; Koziel, J.A.; Cai, L.; Zelle, B.; Sun, G. Performance evaluation of a wood-chip based biofilter using solid-phase microextraction and gas chromatography-mass spectroscopy-olfactometry. Bioresour. Technol. 2008, 99, 7767-7780. [CrossRef] [PubMed]

18. Costa, A.; Chiarello, G.L.; Selli, E.; Guarino, M. Effects of $\mathrm{TiO}_{2}$ based photocatalytic paint on concentrations and emissions of pollutants and on animal performance in a swine weaning unit. J. Environ. Manag. 2012, 96, 86-90. [CrossRef] [PubMed]

19. Guarino, M.; Costa, A.; Porro, M. Photocatalytic $\mathrm{TiO}_{2}$ coating-To reduce ammonia and greenhouse gases concentration and emission from animal husbandries. Bioresour. Technol. 2008, 99, 2650-2658. [CrossRef]

20. Rockafellow, E.M.; Koziel, J.A.; Jenks, W.S. Laboratory-scale investigation of UV treatment of ammonia for livestock and poultry barn exhaust applications. J. Environ. Qual. 2012, 41, 281-288. [CrossRef]

21. Zhu, W.; Koziel, J.; Maurer, D. Mitigation of livestock odors using black light and a new titanium dioxide-based catalyst: Proof-of-concept. Atmosphere 2017, 8, 103. [CrossRef]

22. Hashimoto, K.; Irie, H.; Fujishima, A. $\mathrm{TiO}_{2}$ photocatalysis: A historical overview and future prospects. Jpn. J. Appl. Phys. 2005, 44, 8269. [CrossRef]

23. Schneider, J.; Matsuoka, M.; Takeuchi, M.; Zhang, J.; Horiuchi, Y.; Anpo, M.; Bahnemann, D.W. Understanding $\mathrm{TiO}_{2}$ photocatalysis: Mechanisms and materials. Chem. Rev. 2014, 114, 9919-9986. [CrossRef]

24. Zaleska, A. Doped-TiO 2 : A review. Recent Pat. Eng. 2008, 2, 157-164. [CrossRef]

25. Lee, H.J.; Park, Y.G.; Lee, S.H.; Park, J.H. Photocatalytic Properties of $\mathrm{TiO}_{2}$ According to Manufacturing Method. Korean Chem. Eng. Res. 2018, 56, 156-161. [CrossRef] 
26. Vautier, M.; Guillard, C.; Herrmann, J.-M. Photocatalytic degradation of dyes in water: Case study of indigo and of indigo carmine. J. Catal. 2001, 201, 46-59. [CrossRef]

27. Jia, J.; Li, D.; Wan, J.; Yu, X. Characterization and mechanism analysis of graphite/C-doped $\mathrm{TiO}_{2}$ composite for enhanced photocatalytic performance. J. Ind. Eng. Chem. 2016, 33, 162-169. [CrossRef]

28. Abe, R. Recent progress on photocatalytic and photoelectrochemical water splitting under visible light irradiation. J. Photochem. Photobiol. C Photochem. Rev. 2010, 11, 179-209. [CrossRef]

29. Maeda, K.; Domen, K. Photocatalytic water splitting: Recent progress and future challenges. J. Phys. Chem. Lett. 2010, 1, 2655-2661. [CrossRef]

30. Yang, X.; Zhu, W.; Koziel, J.A.; Cai, L.; Jenks, W.S.; Laor, Y.; van Leeuwen, J.H.; Hoff, S.J. Improved quantification of livestock associated odorous volatile organic compounds in a standard flow-through system using solid-phase microextraction and gas chromatography-mass spectrometry. J. Chromatogr. A 2015, 1414, 31-40. [CrossRef]

31. Valentine, H. A study of the effect of different ventilation rates on the ammonia concentrations in the atmosphere of broiler houses. Br. Poult. Sci. 1964, 5, 149-159. [CrossRef]

32. Wathes, C.; Holden, M.; Sneath, R.; White, R.; Phillips, V. Concentrations and emission rates of aerial ammonia, nitrous oxide, methane, carbon dioxide, dust and endotoxin in UK broiler and layer houses. Br. Poult. Sci. 1997, 38, 14-28. [CrossRef] [PubMed]

33. Wheeler, E.F.; Casey, K.D.; Gates, R.S.; Xin, H.; Zajaczkowski, J.L.; Topper, P.A.; Liang, Y.; Pescatore, A.J. Ammonia emissions from twelve US broiler chicken houses. Trans. Asae 2006, 49, 1495. [CrossRef]

34. Heber, A.J.; Lim, T.-T.; Ni, J.-Q.; Tao, P.-C.; Schmidt, A.M.; Koziel, J.A.; Hoff, S.J.; Jacobson, L.D.; Zhang, Y.; Baughman, G.B. Quality-assured measurements of animal building emissions: Particulate matter concentrations. J. Air Waste Manag. Assoc. 2006, 56, 1642-1648. [CrossRef]

35. Heber, A.J.; Ni, J.-Q.; Lim, T.T.; Tao, P.-C.; Schmidt, A.M.; Koziel, J.A.; Beasley, D.B.; Hoff, S.J.; Nicolai, R.E.; Jacobson, L.D. Quality assured measurements of animal building emissions: Gas concentrations. J. Air Waste Manag. Assoc. 2006, 56, 1472-1483. [CrossRef]

36. Maurer, D.L.; Koziel, J.A.; Bruning, K. Field scale measurement of greenhouse gas emissions from land applied swine manure. Front. Environ. Sci. Eng. 2017, 11, 1. [CrossRef]

37. Levine, S.Z.; Calvert, J.G. The mechanism of the photooxidation of ammonia. Chem. Phys. Lett. 1977, 46, 81-84. [CrossRef]

38. Mozzanega, H.; Herrmann, J.M.; Pichat, P. Ammonia oxidation over UV-irradiated titanium dioxide at room temperature. J. Phys. Chem. 1979, 83, 2251-2255. [CrossRef]

39. Linsebigler, A.L.; Lu, G.; Yates, J.T., Jr. Photocatalysis on $\mathrm{TiO}_{2}$ surfaces: Principles, mechanisms, and selected results. Chem. Rev. 1995, 95, 735-758. [CrossRef]

40. Roman, E.; De Segovia, J. Adsorption of ammonia on $\mathrm{TiO}_{2}$ (001) at room temperature. Surf. Sci. 1991, 251, 742-746. [CrossRef]

41. Henrich, V.E.; Dresselhaus, G.; Zeiger, H. Chemisorbed phases of $\mathrm{H}_{2} \mathrm{O}$ on $\mathrm{TiO}_{2}$ and $\mathrm{SrTiO}_{3}$. Solid State Commun. 1977, 24, 623-626. [CrossRef]

42. Maxime, G.; Amine, A.A.; Abdelkrim, B.; Dominique, W. Removal of gas-phase ammonia and hydrogen sulfide using photocatalysis, nonthermal plasma, and combined plasma and photocatalysis at pilot scale. Environ. Sci. Pollut. Res. 2014, 21, 13127-13137. [CrossRef] [PubMed]

43. Jeong, M.-G.; Park, E.J.; Seo, H.O.; Kim, K.-D.; Kim, Y.D.; Lim, D.C. Humidity effect on photocatalytic activity of $\mathrm{TiO}_{2}$ and regeneration of deactivated photocatalysts. Appl. Surf. Sci. 2013, 271, 164-170. [CrossRef]

44. Seo, H.O.; Park, E.J.; Kim, I.H.; Han, S.W.; Cha, B.J.; Woo, T.G.; Kim, Y.D. Influence of humidity on the photo-catalytic degradation of acetaldehyde over $\mathrm{TiO}_{2}$ surface under UV light irradiation. Catal. Today 2017, 295, 102-109. [CrossRef]

45. Boulinguiez, B.; Bouzaza, A.; Merabet, S.; Wolbert, D. Photocatalytic degradation of ammonia and butyric acid in plug-flow reactor: Degradation kinetic modeling with contribution of mass transfer. J. Photochem. Photobiol. A Chem. 2008, 200, 254-261. [CrossRef]

46. Assadi, A.A.; Bouzaza, A.; Wolbert, D. Photocatalytic oxidation of trimethylamine and isovaleraldehyde in an annular reactor: Influence of the mass transfer and the relative humidity. J. Photochem. Photobiol. A Chem. 2012, 236, 61-69. [CrossRef]

47. Kim, J.S.; Lee, T.K. Effect of humidity on the photocatalytic degradation of trichloroethylene in gas phase over $\mathrm{TiO}_{2}$ thin films treated by different conditions. Korean J. Chem. Eng. 2001, 18, 935-940. [CrossRef] 
48. Amama, P.B.; Itoh, K.; Murabayashi, M. Photocatalytic degradation of trichloroethylene in dry and humid atmospheres: Role of gas-phase reactions. J. Mol. Catal. A Chem. 2004, 217, 109-115. [CrossRef]

49. Yao, H.; Feilberg, A. Characterisation of photocatalytic degradation of odorous compounds associated with livestock facilities by means of PTR-MS. Chem. Eng. J. 2015, 277, 341-351. [CrossRef]

50. Hamdy, M.S. Effect of humidity on the photocatalytic degradation of gaseous hydrocarbons mixture. Mater. Chem. Phys. 2017, 197, 1-9. [CrossRef]

51. Cant, N.W.; Cole, J.R. Photocatalysis of the reaction between ammonia and nitric oxide on $\mathrm{TiO}_{2}$ surfaces. J. Catal. 1992, 134, 317-330. [CrossRef]

52. Wu, H.; Ma, J.; Li, Y.; Zhang, C.; He, H. Photocatalytic oxidation of gaseous ammonia over fluorinated $\mathrm{TiO}_{2}$ with exposed (0 0 1) facets. Appl. Catal. B Environ. 2014, 152, 82-87. [CrossRef]

53. Alonso-Tellez, A.; Robert, D.; Keller, N.; Keller, V. A parametric study of the UV-A photocatalytic oxidation of $\mathrm{H}_{2} \mathrm{~S}$ over $\mathrm{TiO}_{2}$. Appl. Catal. B Environ. 2012, 115, 209-218. [CrossRef]

54. Canela, M.C.; Alberici, R.M.; Jardim, W.F. Gas-phase destruction of $\mathrm{H}_{2} \mathrm{~S}$ using $\mathrm{TiO}_{2} / \mathrm{UV}-\mathrm{VIS}$. J. Photochem. 1998, 112, 73-80. [CrossRef]

55. Yuliati, L.; Yoshida, H. Photocatalytic conversion of methane. Chem. Soc. Rev. 2008, 37, 1592-1602. [CrossRef]

56. Fu, Z.; Yang, Q.; Liu, Z.; Chen, F.; Yao, F.; Xie, T.; Zhong, Y.; Wang, D.; Li, J.; Li, X. Photocatalytic conversion of carbon dioxide: From products to design the catalysts. J. Co2 Util. 2019, 34, 63-73. [CrossRef]

57. Paramasivam, I.; Jha, H.; Liu, N.; Schmuki, P. A review of photocatalysis using self-organized $\mathrm{TiO}_{2}$ nanotubes and other ordered oxide nanostructures. Small 2012, 8, 3073-3103. [CrossRef]

58. Tan, S.S.; Zou, L.; Hu, E. Photocatalytic reduction of carbon dioxide into gaseous hydrocarbon using $\mathrm{TiO}_{2}$ pellets. Catal. Today 2006, 115, 269-273. [CrossRef]

59. Civiš, S.; Ferus, M.; Knížek, A.; Kubelík, P.; Kavan, L.; Zukalová, M. Photocatalytic transformation of $\mathrm{CO}_{2}$ to $\mathrm{CH}_{4}$ and $\mathrm{CO}$ on acidic surface of $\mathrm{TiO}_{2}$ anatase. Opt. Mater. 2016, 56, 80-83. [CrossRef]

60. Kaiser, J.; Röckmann, T.; Brenninkmeijer, C.A.; Crutzen, P.J. Wavelength dependence of isotope fractionation in $\mathrm{N}_{2} \mathrm{O}$ photolysis. Atmos. Chem. Phys. 2003, 3, 303-313. [CrossRef]

61. Armerding, W.; Comes, F.; Schülke, B. O (1D) quantum yields of ozone photolysis in the UV from $300 \mathrm{~nm}$ to its threshold and at $355 \mathrm{~nm}$. J. Phys. Chem. 1995, 99, 3137-3143. [CrossRef]

62. Kolinko, P.; Kozlov, D. Products distribution during the gas phase photocatalytic oxidation of ammonia over the various titania based photocatalysts. Appl. Catal. B Environ. 2009, 90, 126-131. [CrossRef]

63. Kočí, K.; Reli, M.; Troppová, I.; Šihor, M.; Kupková, J.; Kustrowski, P.; Praus, P. Photocatalytic decomposition of $\mathrm{N}_{2} \mathrm{O}$ over $\mathrm{TiO}_{2} / g-\mathrm{C}_{3} \mathrm{~N}_{4}$ photocatalysts heterojunction. Appl. Surf. Sci. 2017, 396, 1685-1695. [CrossRef]

64. Wang, H.; Sun, Z.; Li, Q.; Tang, Q.; Wu, Z. Surprisingly advanced $\mathrm{CO}_{2}$ photocatalytic conversion over thiourea derived $\mathrm{g}-\mathrm{C}_{3} \mathrm{~N}_{4}$ with water vapor while introducing 200-420 nm UV light. J. Co2 Util. 2016, 14, 143-151. [CrossRef]

65. Ohtani, B.; Zhang, S.-W.; Nishimoto, S.-i.; Kagiya, T. Catalytic and photocatalytic decomposition of ozone at room temperature over titanium (IV) oxide. J. Chem. Soc. Faraday Trans. 1992, 88, 1049-1053. [CrossRef]

66. Černigoj, U.; Štangar, U.L.; Trebše, P. Degradation of neonicotinoid insecticides by different advanced oxidation processes and studying the effect of ozone on $\mathrm{TiO}_{2}$ photocatalysis. Appl. Catal. B Environ. 2007, 75, 229-238. [CrossRef]

67. Hernández-Alonso, M.a.D.; Coronado, J.M.; Maira, A.J.; Soria, J.; Loddo, V.; Augugliaro, V. Ozone enhanced activity of aqueous titanium dioxide suspensions for photocatalytic oxidation of free cyanide ions. Appl. Catal. B Environ. 2002, 39, 257-267. [CrossRef]

68. Pichat, P.; Cermenati, L.; Albini, A.; Mas, D.; Delprat, H.; Guillard, C. Degradation processes of organic compounds over UV-irradiated $\mathrm{TiO}_{2}$. Effect of ozone. Res. Chem. Intermed. 2000, 26, 161-170. [CrossRef]

69. Pichat, P.; Disdier, J.; Hoang-Van, C.; Mas, D.; Goutailler, G.; Gaysse, C. Purification/deodorization of indoor air and gaseous effluents by $\mathrm{TiO}_{2}$ photocatalysis. Catal. Today 2000, 63, 363-369. [CrossRef]

(C) 2020 by the authors. Licensee MDPI, Basel, Switzerland. This article is an open access article distributed under the terms and conditions of the Creative Commons Attribution (CC BY) license (http://creativecommons.org/licenses/by/4.0/). 